\title{
Spatial Impulse Wave Generation and Propagation
}

\section{Journal Article}

Author(s):

Evers, Frederic M. (D); Hager, Willi H.; Boes, Robert (D)

Publication date:

2019-05

Permanent link:

https://doi.org/10.3929/ethz-b-000331784

\section{Rights / license:}

In Copyright - Non-Commercial Use Permitted

Originally published in:

Journal of Waterway, Port, Coastal, and Ocean Engineering 145(3), https://doi.org/10.1061/(ASCE)WW.1943-5460.0000514

Funding acknowledgement:

143657 - Spatial impulse waves (SNF) 


\title{
Spatial impulse wave generation and propagation
}

\author{
Frederic M. Evers' ${ }^{1}$; Willi H. Hager, F.ASCE2; and Robert M. Boes ${ }^{3}$
}

\begin{abstract}
Rapid landslides into water bodies may generate massive water waves posing a threat to riparian settlements and infrastructure. These waves are referred to as impulse waves and exhibit tsunami-like characteristics. The generation and in particular the spatial propagation of impulse waves was studied in a hydraulic laboratory wave basin. A videometric measurement system was applied to track the water surface displacement. Compared to fixed wave gauges typically applied in previous studies, this technique yields a quasi-continuous representation of the water surface allowing for a detailed analysis of spatial propagation patterns. In total 74 experiments with deformable mesh-packed slides were conducted thereby varying the slide impact velocity, the slide mass, the slide thickness, the slide width, the slide impact angle, and the stillwater depth. Empirically derived prediction equations are presented and discussed for key wave characteristics including wave amplitudes and celerities. In the context of a preliminary hazard assessment, these equations allow for the estimation of wave magnitudes at prototype-scale.
\end{abstract}

Author keywords: Impulse wave; Landslide; Physical modelling; Prediction method; Spatial wave propagation.

\section{Introduction}

If a landslide, an avalanche, or glacier calving interacts with a large body of water, massive waves may be generated. The wave generation mechanism involves a momentum transfer from the slide mass to the water column. Waves generated by extremely rapid gravity-driven subaerial mass movements are commonly referred to as impulse waves (Heller et al. 2009) and may be observed in coastal areas as well as in inland waters (Roberts et al. 2014). An impulse wave event involves three phases as shown in Fig. 1. During the wave generation phase, the subaerial slide mass transfers its momentum to the water column, thereby generating a wave train with several crests and troughs. The amplitudes and wave lengths of the wave train are transformed in the wave propagation stage. Depending on the bathymetry of the water body, these transformation effects include refraction, diffraction, and shoaling (Heller et al. 2009). In addition, the waves are subject to frequency and amplitude dispersion (Heller and Hager 2010). Wave runup (e.g. Müller 1995, McFall and Fritz 2017), overland flow (e.g. Fuchs and Hager 2015), or wave overtopping (e.g. Müller 1995, Kobel et al. 2017) characterize the wave impact phase. The first two phases are in the scope of this study.

Wave generation
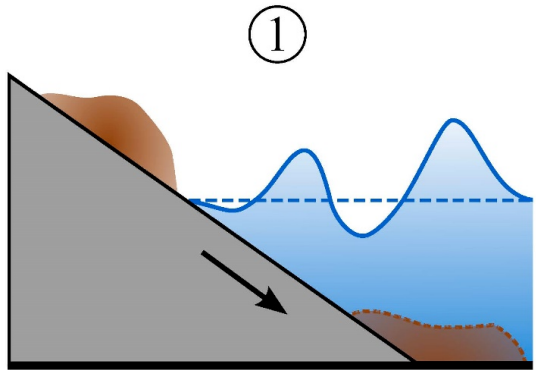

Wave propagation
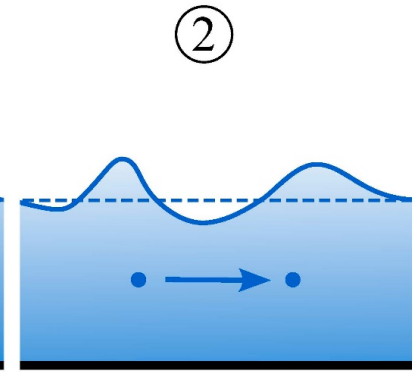

\section{Wave impact}
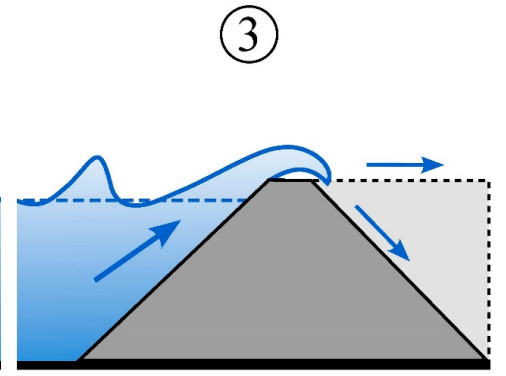

Fig. 1. Phases of landslide generated impulse wave event: (1) wave generation, (2) wave propagation, and (3) wave impact including wave runup, overland flow, and dam overtopping (Evers 2017, with permission)

A multitude of impulse wave events have been reported in the past. One of the most prominent cases is the impulse wave event in Lituya Bay, USA, which was triggered by an earthquake in 1958 and caused runup heights of more than $500 \mathrm{~m}$ (Miller 1960). Bornhold et al. (2007) describe a historical example in the sixteenth century, when impulse waves generated by a rockslide at Knight Inlet, Canada, presumably destroyed an indigenous settlement. Impulse wave events of the $21^{\text {st }}$ century involving subaerial landslides in coastal areas include Paatuut, Greenland,

\footnotetext{
${ }^{1}$ Postdoctoral Researcher, Laboratory of Hydraulics Hydrology and Glaciology (VAW), ETH Zurich, CH-8093 Zürich, Switzerland, evers@vaw.baug.ethz.ch, ORCID 0000-0001-5181-8978 (corresponding author)

${ }^{2}$ Emeritus Professor, Laboratory of Hydraulics Hydrology and Glaciology (VAW), ETH Zurich, CH-8093 Zürich, Switzerland, hager@vaw.baug.ethz.ch

${ }^{3}$ Professor and Director, Laboratory of Hydraulics Hydrology and Glaciology (VAW), ETH Zurich, CH-8093 Zürich, Switzerland, boes@vaw.baug.ethz.ch, ORCID 0000-0002-0319-976X
} 
in 2000 (Dahl-Jensen et al. 2004), Aysén Fjord, Chile, in 2007 (Sepúlveda et al. 2010), Taan Fjord, USA, in 2015 (George et al. 2017, Higman et al. 2018), and Karrat Fjord, Greenland, in 2017 (Poli 2017). A well-documented event in inland waters occurred in 2007 when a three million cubic meters landslide impacted Chehalis Lake, Canada, and caused runup heights of $38 \mathrm{~m}$ at the opposite shore (Roberts et al. 2013, Wang et al. 2015). In the case of a water body impounded behind an artificial or natural dam structure, impulse wave overtopping may have a devastating impact on downstream areas. The wave overtopping event at Vajont Dam, Italy, in 1963 claimed nearly 2000 fatalities (Genevois and Ghirotti 2005). Risley et al. (2006) conducted a hazard analysis of potential impulse wave overtopping at the Usoi landslide dam, Tajikistan. A global overview with 254 events covering both inland and coastal waters was compiled by Roberts et al. (2014).

Based on the slide properties and the bathymetry, a prediction of the generated wave magnitude may be conducted. Heller et al. (2009) describe five different prediction methods within the context of hazard assessment: (1) generally applicable equations developed from model tests, (2) prototype-specific model tests, (3) numerical simulations, (4) empirical equations derived from field data, and (5) analytical investigations. Heller et al. (2009) and Evers et al. (2018) discuss the capabilities and limitations of these methods. Item (1) yields estimated wave magnitudes at low cost and time requirements. Therefore, this method is advantageous when an event is imminent or as a first assessment to determine whether additional more accurate investigations are needed.

Two types of impulse wave propagation patterns are commonly investigated in model tests: unidirectional and omnidirectional. While the former is investigated in wave flumes (2D), e.g. by Fritz et al. (2004), Zweifel et al. (2006), and Di Risio and Sammarco (2008), the latter is studied in wave basins (3D). Generally applicable equations developed from model tests accounting for omnidirectional impulse wave propagation were presented by Panizzo et al. (2005), Heller et al. (2009), Mohammed and Fritz (2012), Heller and Spinneken (2015), and McFall and Fritz (2016). Evers and Hager (2016a) applied the equations of the former four 3D studies to selected experiments of this study's data set to assess their applicability on an extended range of test parameters. They found limitations regarding slide model replication, i.e. rigid block vs. deformable granular slides, constant test parameters, e.g. a single slide impact angle or slide width, or a lack of experimental validation. In addition, all studies were based on wave gauge data from a limited number of measurement locations. Bregoli et al. (2017) demonstrated the advantages of a videometric measurement approach: First, this approach allows for a continuous representation of the water surface and therefore an adaptive tracking of specific wave conditions in the impact region. Second, in contrast to capacitance wave gauges, the measurement devices may not be damaged by the impacting slide mass. Note that the measurement approach by Bregoli et al. (2017) was limited to a single wave propagation direction along the slide axis, although their experiments were conducted in a wave basin.

The main objective of this study is to advance the understanding of spatial propagation of landslide generated impulse waves by applying a videometric measurement technique to track arbitrary water surfaces in 3D. For designing protection measures against wave impact, engineers require quantitative information on expected wave magnitudes at a certain location depending on its position relative to the wave source. Therefore, generally applicable empirical prediction equations are derived from a broad set of slide parameters for key wave characteristics to improve the quality of hazard assessments.

\section{Physical model}

\section{Experimental setup}

The experiments were conducted in a $4.5 \mathrm{~m}$ by $8 \mathrm{~m}$ wave basin $0.75 \mathrm{~m}$ high (Fig. 2). The impulse waves were generated with a movable chute featuring an inclinable sliding plane, a release box, and lateral guidance walls. The sliding plane allowed for impact angles of $30^{\circ}, 45^{\circ}, 60^{\circ}$, and $90^{\circ}$. Mesh-packed slides were applied, allowing for a simplified handling similar to rigid slides while maintaining a granular matrix and deformability. Evers and Hager (2015a) showed that the impulse wave characteristics generated by this type of slide are predictable with empirical equations derived from experiments with free granular slides within a similar scatter range, e.g. $\pm 30 \%$ for the wave height, provided that the slide centroid velocity is the reference velocity in both cases. The meshpacked slides were composed of granular material loosely filled into bags made of sifting media (SEFAR, NYTAL PA-38GG-500, Sefar AG, Heiden, Switzerland) with a mesh opening of $500 \mu \mathrm{m}$ and $47 \%$ porosity. The granular material was made of $87 \% \mathrm{BaSO}_{4}$ and $13 \% \mathrm{PP}$ of grain (subscript $g$ ) diameter $d_{g}=8 \mathrm{~mm}$, grain density $\rho_{g}=2,420$ 
$\mathrm{kg} / \mathrm{m}^{3}$, and a bulk slide density $\rho_{s}=1,338 \mathrm{~kg} / \mathrm{m}^{3}$ (Heller 2008). The release box allowed for predefining the slide geometry including the slide width between $0.25 \mathrm{~m}$ and $1.00 \mathrm{~m}$. The slides were accelerated by gravity from various drop heights after manual release from the box. During acceleration, the slide deformation was found negligible and the slide centroid velocity was consequently equal to the slide front velocity. The latter was measured with two Laser Light Barriers (OHDK 14, Baumer Electric AG, Frauenfeld, Switzerland) mounted perpendicular to the sliding plane. The sensors' short response time $<0.5 \mathrm{~ms}$ resulted in a measurement accuracy of approximately $\pm 5 \%$ for the maximum measured slide impact velocity of $4.76 \mathrm{~m} / \mathrm{s}$ over a measuring section of $0.1 \mathrm{~m}$. A porous filter foam was placed in the basin acting as wave damper to reduce the waiting time between experimental runs.

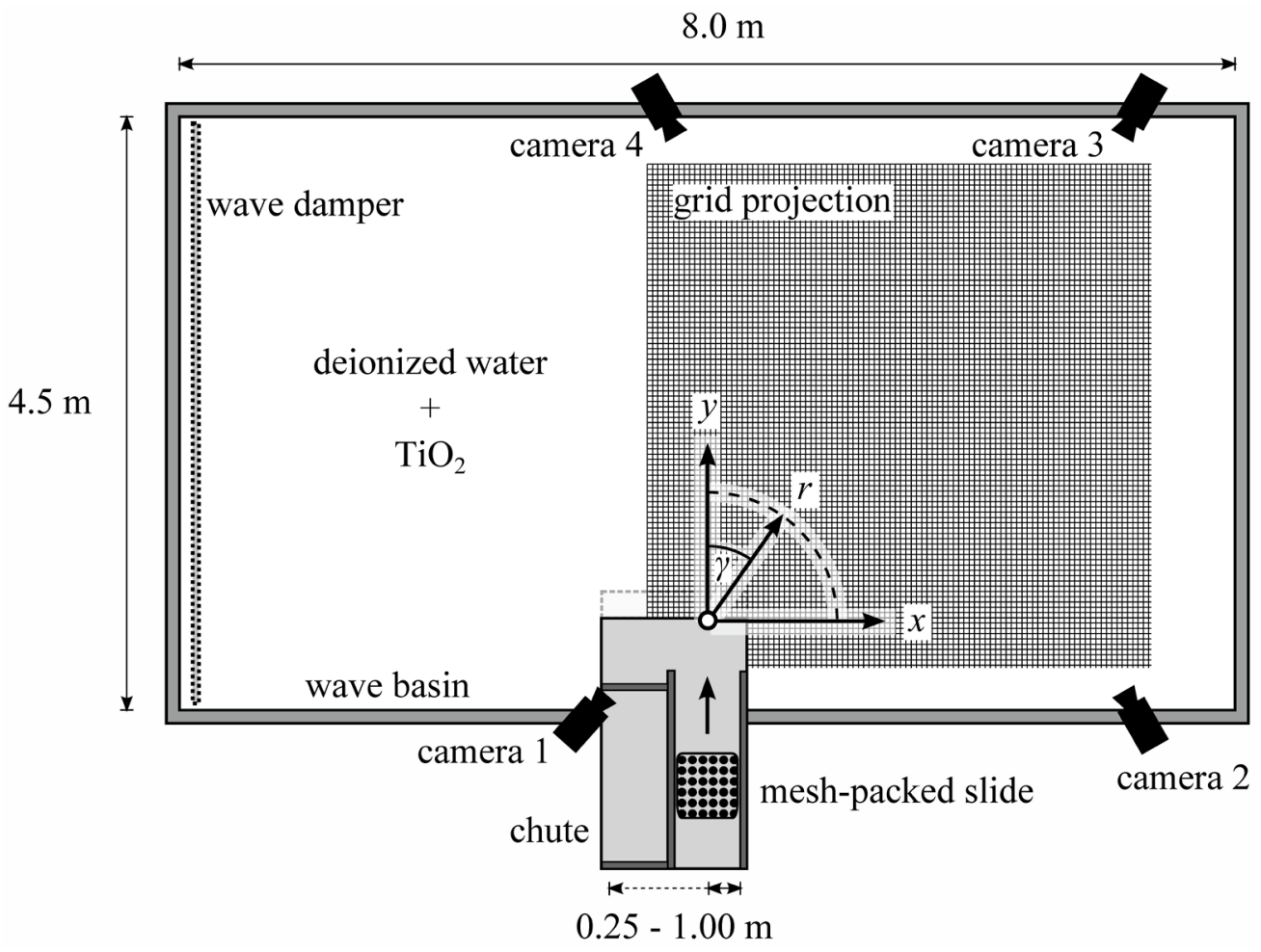

Fig. 2. Experimental setup of $3 \mathrm{D}$ wave basin (adapted from Evers 2017)

\section{Water surface tracking and test repeatability}

The application of a videometric measurement system required an opaque fluid allowing for the projection of a grid pattern on the free surface. Therefore, deionized water was mixed with $4 \mathrm{~kg} / \mathrm{m}^{3}$ titanium dioxide $\left(\mathrm{TiO}_{2}\right)$ pigments (KRONOS 1002, KRONOS Worldwide, Inc., Dallas, USA) as demonstrated by Przadka et al. (2012) and Evers and Hager (2015b). The addition of $\mathrm{TiO}_{2}$ had negligible effects on the water viscosity and surface tension (Przadka et al. 2012). A regular grid pattern with $79 \times 79$ intersections was projected onto the water surface with a projector (Götschmann G 67 P, Gecko-Cam GmbH, Putzbrunn, Germany), thereby defining the measurement zone. As the general wave propagation pattern is considered symmetrical, the measurement zone covered only half of the full wave pattern (Fig. 2). For a slide width of $1 \mathrm{~m}$, the chute allows for a completely symmetrical setup. For slide widths of $0.25 \mathrm{~m}$ and $0.5 \mathrm{~m}$ the sliding plane extends towards $-x$ (Fig. 2). However, the influence of this limited shore extension is assumed to be negligible for wave propagation towards $x$. The commercially available ProSurf-system (AICON 3D Systems GmbH, Braunschweig, Germany) was applied to track the spatial positions of the grid intersections. It comprised four cameras positioned around the wave basin (Fig. 2), synchronized by a control box to an acquisition rate of $24 \mathrm{~Hz}$. The cameras' spatial positions and orientations were calibrated, enabling the tracking of the grid intersection by triangulation (Evers 2017). 

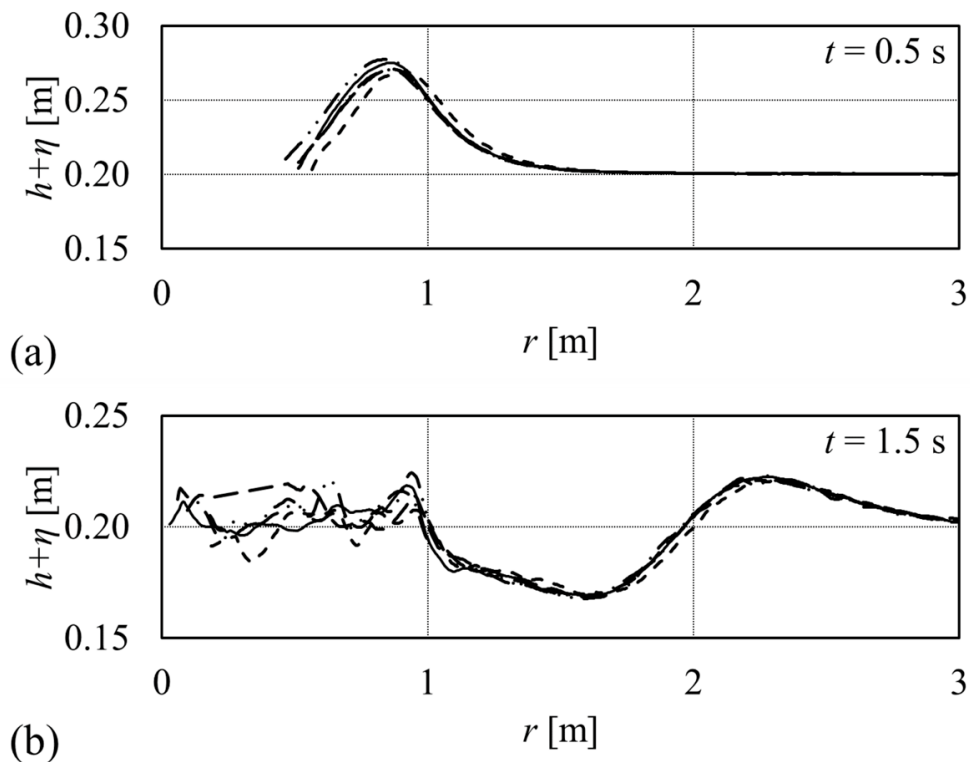

(b)

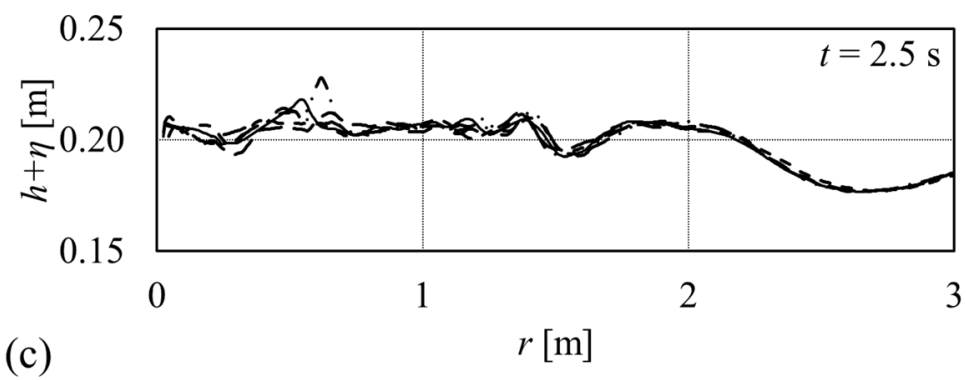

Fig. 3. Water surface profiles $[h+\eta](r)$ of five experimental runs with similar governing parameters for wave propagation angle $\gamma=0^{\circ}$

Fig. 3 shows the water surface profiles of five experimental runs repeated with identical preset parameters at $t=$ $0.5 \mathrm{~s}, 1.5 \mathrm{~s}$, and $2.5 \mathrm{~s}$. Within the vicinity of the slide impact location at $r=0 \mathrm{~m}$, the measured profiles feature larger deviations, while wave crests and troughs are captured sufficiently consistent and detailed for larger propagation distances. However, the deviations are not necessarily related to inaccuracies of the measurement system but are also caused by the repeatability of the experiments; e.g. the slide impact velocities range within the measurement accuracy of the laser light barriers between $4.35 \mathrm{~m} / \mathrm{s}$ and $4.55 \mathrm{~m} / \mathrm{s}$. The measurement accuracy of the videometric system was discussed by Frank and Hager (2014). They found absolute deviations of $<2 \mathrm{~mm}$ to point gauge measurements of solid surfaces. Evers and Hager (2015b) compared the videometrically tracked water level displacements with those measured with capacitance wave gauges and found good overall agreement. Based on the given findings, the measurement accuracy for water surface tracking was estimated to $\pm 1 \mathrm{~mm}$.

\section{Process description}

\section{Governing parameters}

Both, the governing wave generation parameters as well as the targeted wave characteristics are shown in Fig. 4. The wave generation parameters include the slide impact velocity $V_{s}$, the slide mass $m_{s}$, the slide thickness $s$, the slide width $b$, the slide impact angle $\alpha$, and stillwater depth $h$. The wave characteristics included into the analysis are first wave crest amplitude $a_{c 1}$, the first wave trough amplitude $a_{t 1}$, the first wave height $H_{1}$, the first wave period $T_{1}$, the second wave crest amplitude $a_{c 2}$, as well as the celerities of the first and the second wave crests $c_{c 1}$ and $c_{c 2}$. The positions of the respective wave features were defined within a polar coordinate system with the pole representing the slide impact location and the angular and radial coordinates equaling the wave propagation angle $\gamma$ and distance $r$, respectively. 
(a)

(b)
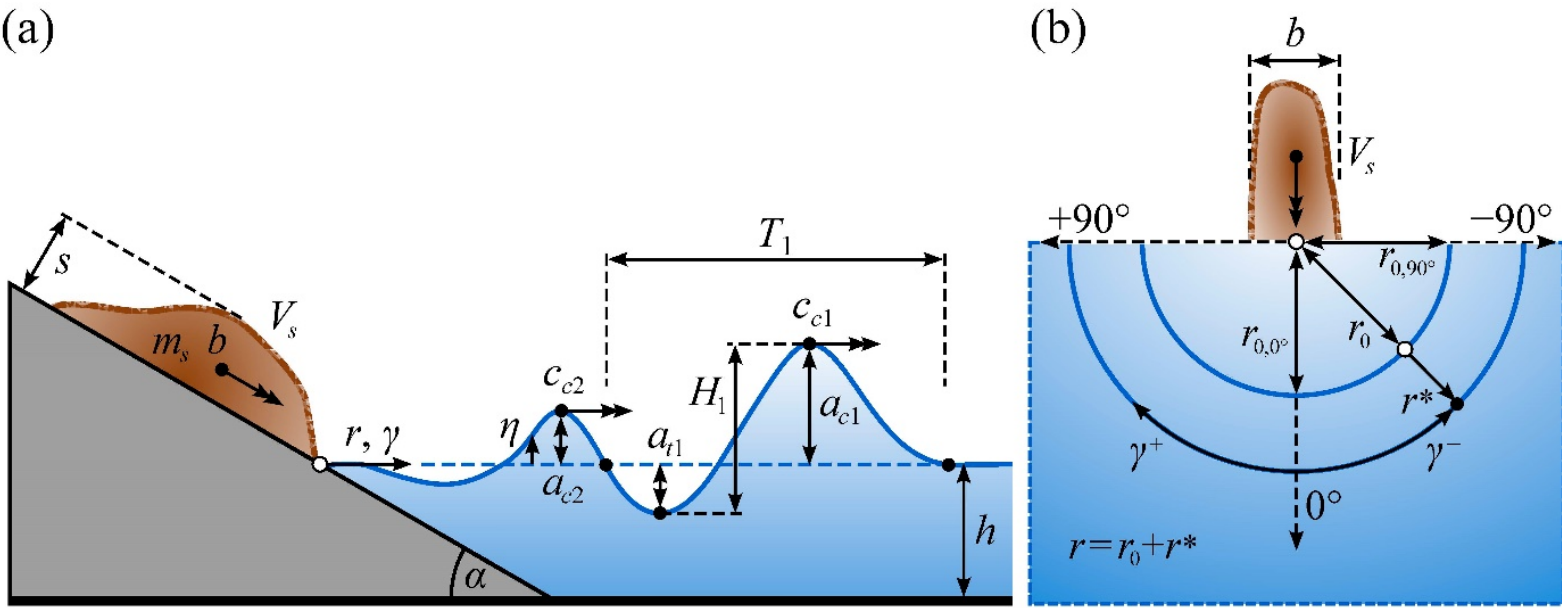

Fig. 4. Definition plot for spatial impulse wave propagation with governing parameters and wave characteristics with (a) side view, (b) plan view (adapted from Evers 2017)

The dimensionless quantities derived from the governing wave generation parameters include the slide Froude number $\mathrm{F}$, the relative slide mass $M$, the relative slide thickness $S$, and the relative slide width $B$, defined as

$$
\begin{aligned}
& \mathrm{F}=V_{s} /(g h)^{0.5} \\
& M=m_{s} /\left(\rho_{w} b h^{2}\right) \\
& S=s / h \\
& B=b / h .
\end{aligned}
$$

Most existing empirical equations for the prediction of wave characteristics include these parameters (Di Risio et al. 2011, Evers and Hager 2016a). The first three parameters F, $M$, and $S$ were included by Heller and Hager (2010) into the impulse product parameter $\mathrm{P}$, describing impulse wave propagation in $2 \mathrm{D}$ wave channels, defined as

$$
\mathrm{P}=\mathrm{F} S^{0.5} M^{0.25}\{\cos ([6 / 7] \alpha)\}^{0.5} .
$$

Table 1 gives an overview of the experimental parameter ranges. The complete dataset including the experimental parameters is provided by Evers (2018). A total of 74 experiments were conducted and analyzed. The test numbers given in this article refer to these according to Evers (2018).

Table 1. Overview of experimental quantities

\begin{tabular}{cc}
\hline Parameter & Test range \\
\hline$V_{s}[\mathrm{~m} / \mathrm{s}]$ & $0.72-4.76$ \\
$m_{s}[\mathrm{~kg}]$ & $10-40$ \\
$s[\mathrm{~m}]$ & $0.06-0.12$ \\
$b[\mathrm{~m}]$ & $0.25-1.00$ \\
$\alpha\left[^{\circ}\right]$ & $30-90$ \\
$h[\mathrm{~m}]$ & $0.2-0.4$ \\
$\mathrm{~F}$ & $0.40-3.40$ \\
$M$ & $0.25-1.00$ \\
$S$ & $0.15-0.6$ \\
$B$ & $0.83-5.00$ \\
$\mathrm{P}$ & $0.13-2.08$ \\
\hline
\end{tabular}


The propagation distance of an outgoing impulse wave train within the basin was limited by the vertical side walls. Wave reflection was accounted for by extrapolating the position of the first initial uplifting of the stillwater level closest to one of the basin walls both in space and time. The extrapolation involved the propagation celerity of the first initial uplifting before reflection as well as the residence time at the wall (Chen et al. 2015). Wave features affected by reflection from the side walls were excluded from the analysis. To avoid significant scale effects, the tests were conducted with stillwater depths $h \geq 0.20 \mathrm{~m}$ (Heller et al. 2008).

\section{Water surface evolution}

The application of the videometric measurement system yields a quasi-continuous contour representation of the water surface. Fig. 5 shows oblique views of the grid projection of Test 043 (Evers 2018). At $t=0.179 \mathrm{~s}$, the splash screen of the impact crater has attained its highest elevation level. The impact crater then collapses up to $0.750 \mathrm{~s}$. While the first wave crest is then hardly visible, the first wave trough has clearly formed at $t=1.125 \mathrm{~s}$. The water surface close to the slide impact location is irregularly distorted at this stage. At $t=1.500 \mathrm{~s}$, the second wave crest forms. Note the spilling second wave crest for small wave propagation angles $\gamma$. The second wave crest has further propagated at $t=1.875 \mathrm{~s}$ along with reduced wave spilling.
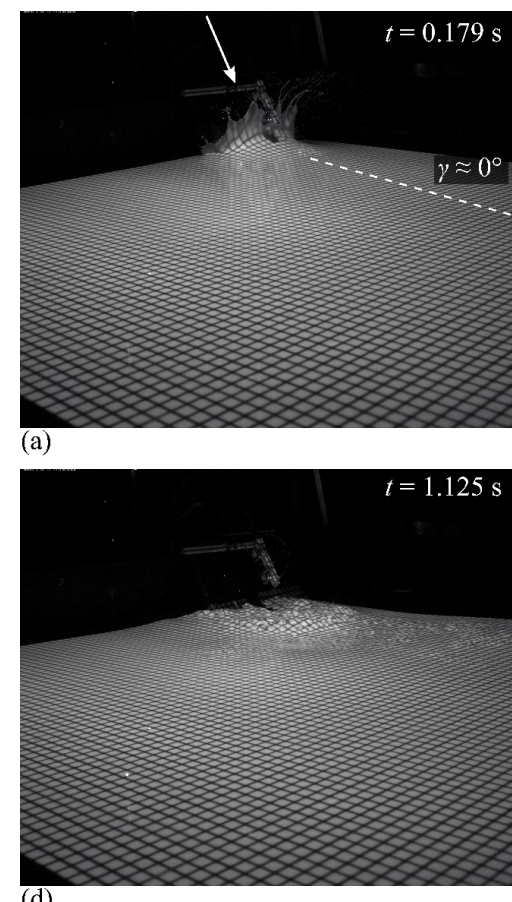

(d)

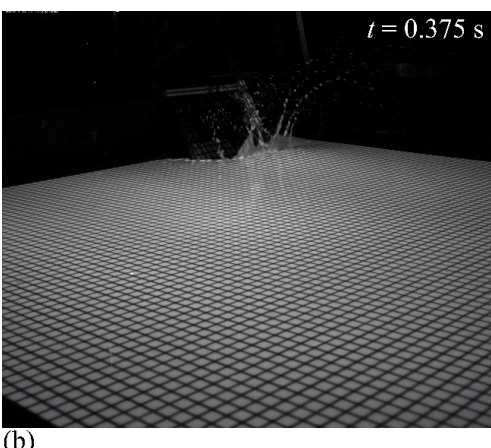

(b)

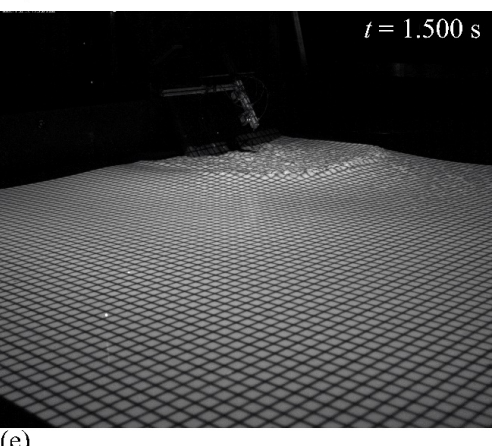

(e)

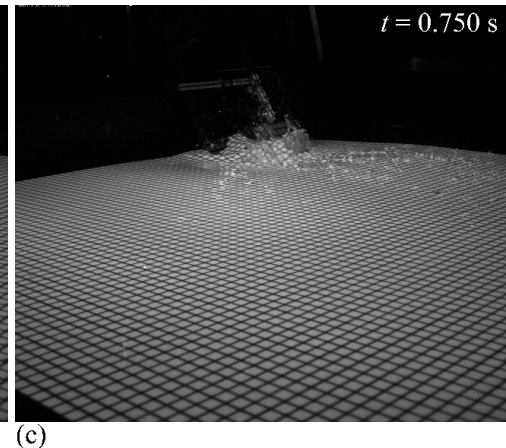

(c)

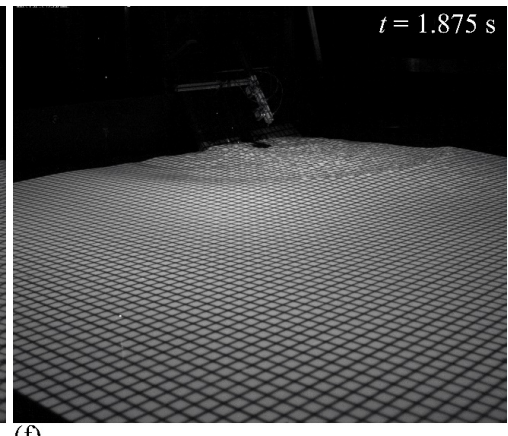

(f)

Fig. 5. Oblique view of Test 043 (Evers 2018) with $V_{s}=2.38 \mathrm{~m} / \mathrm{s}, m_{s}=20 \mathrm{~kg}, s=0.06 \mathrm{~m}, b=0.50 \mathrm{~m}, \alpha=60^{\circ}, h=0.40 \mathrm{~m}$, and $\mathrm{P}=0.26$ (adapted from Evers 2017)

Fig. 6 shows the contour plots of Test 043 as in Fig. 5. These plots were produced by interpolating between the projected grid intersections tracked by the videometric measurement system. Note that Fig. 6 starts at $t=0.375 \mathrm{~s}$, while Fig. 5 includes $t=0.179 \mathrm{~s}$ as the first time step. The slide impacts the water surface at $t=0 \mathrm{~s}$ at the origin of the $y$-axis. At $t=0.375 \mathrm{~s}$, the first wave crest has just emerged; it has a large amplitude for $\gamma=0^{\circ}(y$-axis), decreasing toward $\gamma=90^{\circ}$ ( $x$-axis). The blank area close to the impact location arises from the simultaneous collapse of the impact crater. The continuous tracking of the water surface is limited by the strong deformation of the water surface. At $t=0.750 \mathrm{~s}$, the first wave crest propagated to $r \approx 1.1 \mathrm{~m}$ and is subjected to amplitude decay. The first trough of the wave train emerges at the same time. At $t=1.125 \mathrm{~s}$, the first wave trough is fully captured by the videometric measurement system. The water surface around the impact location is strongly distorted and consequently the blank area increases. The second wave crest is fully developed at $t=1.500 \mathrm{~s}$ and has further propagated at $t=1.875 \mathrm{~s}$, while the first wave crest has partially left the measurement area. A second wave trough has formed at $t=2.250 \mathrm{~s}$. A qualitative visual comparison with the first wave shown at full extent at $t=1.125 \mathrm{~s}$ reveals that the wave length of the second wave is substantially shorter, which was also observed by Mohammed and Fritz (2012) as well as McFall and Fritz (2016). However, note that the water surface for propagation distances 
This material may be downloaded for personal use only. Any other use requires prior permission of the American Society of Civil Engineers. This material may be found at https://doi.org/10.1061/(ASCE)WW.1943-5460.0000514.

$r>1.5 \mathrm{~m}$ at $t=2.250 \mathrm{~s}$ is potentially affected by reflections from the basin sidewalls; the second wave trough amplitude was not included in the quantitative analysis, therefore.
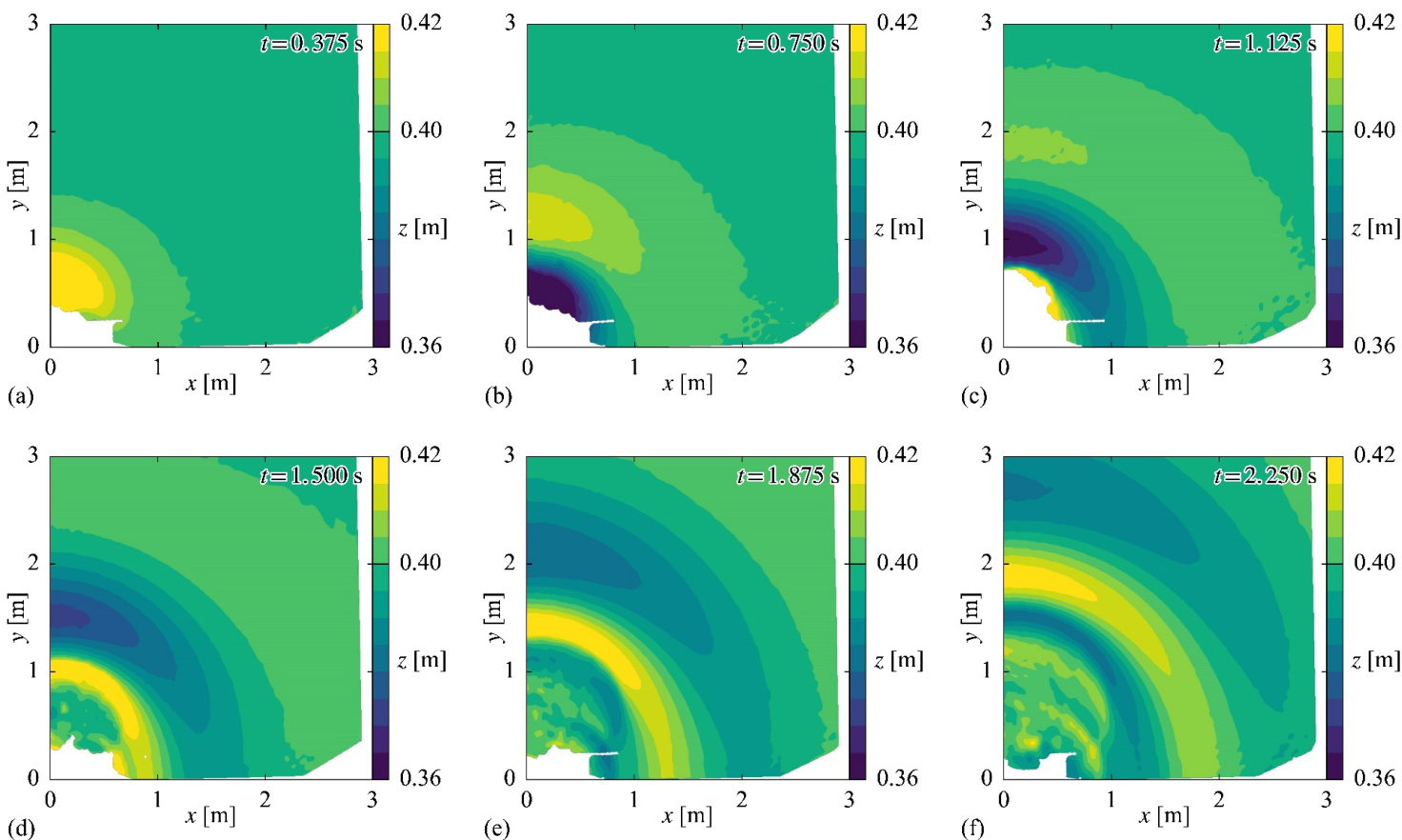

Fig. 6. Contour plots $z(x, y)$ of Test 043 (Evers 2018)
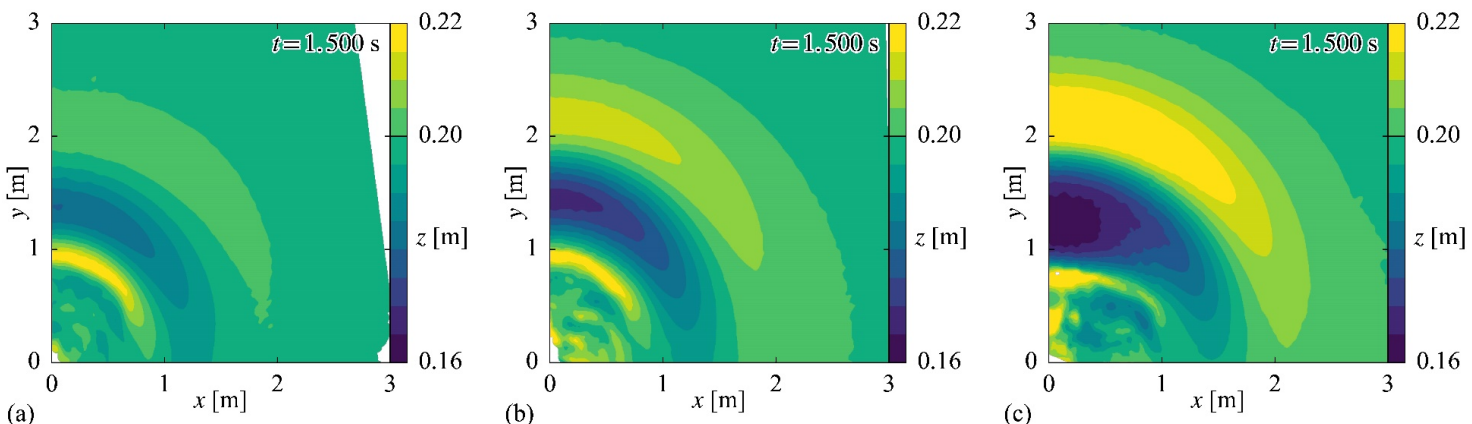

Fig. 7. Contour plots $z(x, y)$ of Tests 072,004 , and 059 (Evers 2018) with $\left[V_{s} ; m_{s} ; s ; b ; \alpha ; h, \mathrm{P}\right]$ (a) $\left[3.03 \mathrm{~m} / \mathrm{s} ; 10 \mathrm{~kg} ; 0.06 \mathrm{~m} ; 0.25 \mathrm{~m} ; 60^{\circ}\right.$; $0.20 \mathrm{~m} ; 0.93]$, (b) [2.70 m/s; $\left.20 \mathrm{~kg} ; 0.06 \mathrm{~m} ; 0.50 \mathrm{~m} ; 60^{\circ} ; 0.20 \mathrm{~m} ; 0.83\right]$, and (c) $\left[2.78 \mathrm{~m} / \mathrm{s} ; 40 \mathrm{~kg} ; 0.06 \mathrm{~m} ; 1.00 \mathrm{~m} ; 60^{\circ} ; 0.20 \mathrm{~m} ; 0.86\right]$

The effect of slide width $b$ on spatial impulse wave propagation is shown in Fig. 7. All plots refer to the identical instant at $t=1.500 \mathrm{~s}$ for three different experimental runs. While their impulse product parameters $\mathrm{P}$ were similar, the slide widths were $b=0.25 \mathrm{~m}, 0.50 \mathrm{~m}$, and $1.00 \mathrm{~m}$, respectively. The first wave crest amplitudes $a_{c 1}(y \approx 2 \mathrm{~m})$ increase significantly with increasing slide width for spatial, i.e. $3 \mathrm{D}$, wave propagation. In contrast, $\mathrm{P}$ was derived from experiments in a wave flume. In this $2 \mathrm{D}$ type of setup, a doubling of the flume width along with slide width $b$ and the slide mass $m_{s}$ has no effect on the generated wave magnitudes (Evers and Hager 2016b). Fig. 7 demonstrates that the effect of $b$ has to be accounted for in 3D water bodies to allow for the prediction of spatial impulse wave propagation. 
This material may be downloaded for personal use only. Any other use requires prior permission of the American Society of Civil Engineers. This material may be found at https://doi.org/10.1061/(ASCE)WW.1943-5460.0000514.
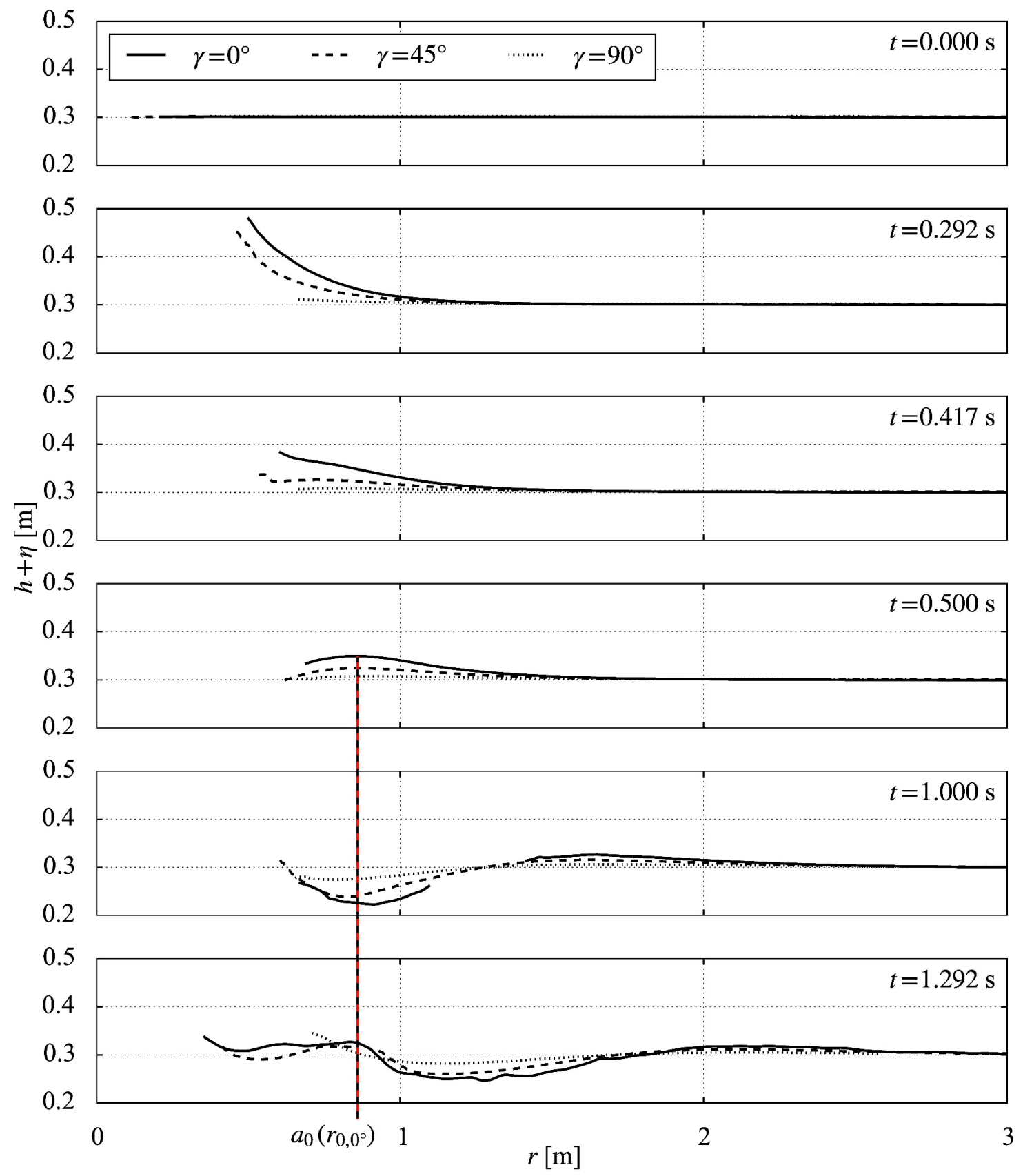

Fig. 8. Profile plots $[h+\eta](r)$ of Test 033 (Evers 2018) including impact radius $r_{0}$ and initial first wave crest amplitude $a_{0, c 1}$ with $V_{s}=$ $4.55 \mathrm{~m} / \mathrm{s}, m_{s}=20 \mathrm{~kg}, s=0.12 \mathrm{~m}, b=0.50 \mathrm{~m}, \alpha=60^{\circ}, h=0.30 \mathrm{~m}$, and $\mathrm{P}=1.08$ at $\gamma=0^{\circ}, 45^{\circ}, 90^{\circ}$

Fig. 8 shows the water surface profiles for $\gamma=0^{\circ}, 45^{\circ}$, and $90^{\circ}$ during the wave generation process. The water surface is undisturbed at $t=0.000 \mathrm{~s}$. At $t=0.292 \mathrm{~s}$, the impacting slide creates an impact crater and displaces the water surface. The crater collapses and the first wave crest starts to emerge from the slide impact zone at $t=$ $0.417 \mathrm{~s}$. The crest is fully developed at $t=0.500 \mathrm{~s}$. The wave propagation distance $r$ of the initial first wave crest amplitude $a_{0, c 1}$ is defined as the impact radius $r_{0}$. At $t=1.000 \mathrm{~s}$ and $1.292 \mathrm{~s}$ the respective water surface profiles show that also the initial first wave trough and second wave crest amplitudes are formed at the impact radius $r_{0}$.

The wave generation and propagation process is divided into two zones: (I) slide impact zone and (II) wave propagation zone (Fig. 9). The impact radius $r_{0}$ separates these two zones. Zone I is affected by the generation of the impact crater and its collapse, involving strong turbulence and air entrainment. Distinct wave characteristics, e.g. wave amplitudes, become quantifiable first in Zone II by applying the videometric measurement system (Fig. 
This material may be downloaded for personal use only. Any other use requires prior permission of the American Society of Civil Engineers. This material may be found at https://doi.org/10.1061/(ASCE)WW.1943-5460.0000514.

8). In addition to the wave propagation angle $\gamma$, the surrogate radial wave propagation distance $r^{*}=r-r_{0}$ describes the outgoing impulse wave train beyond $r_{0}$ within the polar coordinate system (Fig. $4 \mathrm{~b}$ and Fig. 9).

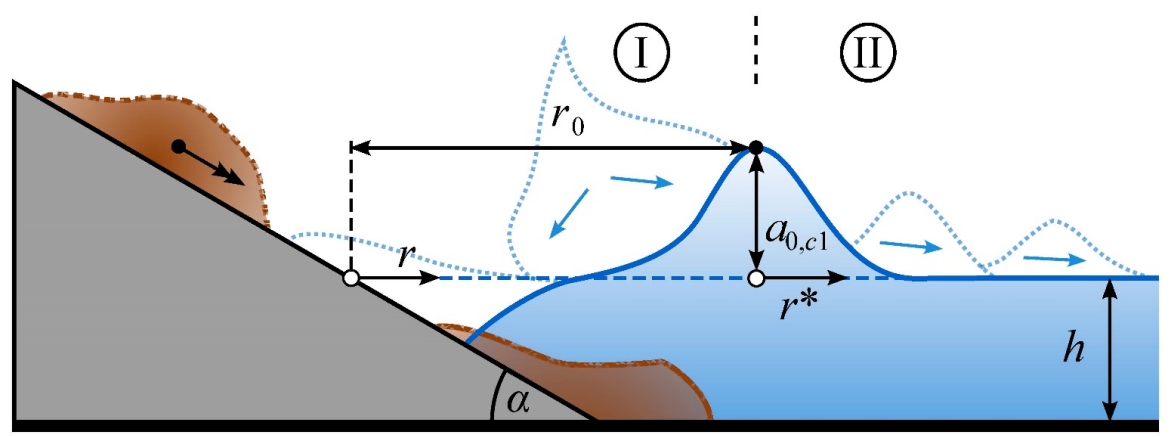

Fig. 9. Definition plot of impact radius $r_{0}$ and the initial amplitude of the first wave crest $a_{0, c 1}$

The first wave crest amplitudes $a_{c 1}$, i.e the shape of the first wave crest, is plotted versus the wave propagation angle $\gamma$ in Fig. 10(a), for time steps between $t=0.38 \mathrm{~s}$ and $2.17 \mathrm{~s}$. During propagation, $a_{c 1}$ decreases for all $\gamma$. However, the decay rate is higher for $\gamma=0^{\circ}$ than for $90^{\circ}$ (Fig. 10). While $a_{c 1,90^{\circ}}$ accounts for $8 \%$ of $a_{c 1,0^{\circ}}$ at $t=$ $0.38 \mathrm{~s}$, this ratio increases to $43 \%$ at $t=2.17 \mathrm{~s}$ (Fig. 10b). This indicates a lateral spreading effect on the wave crest normal to its propagation direction.

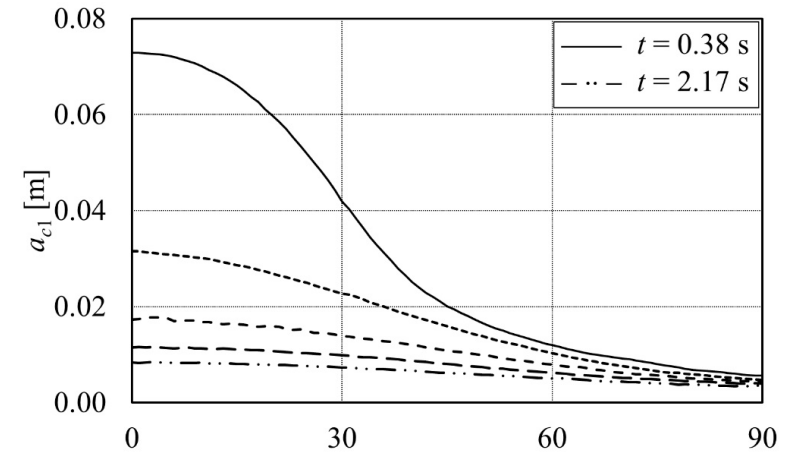

(a) $\gamma\left[{ }^{\circ}\right]$

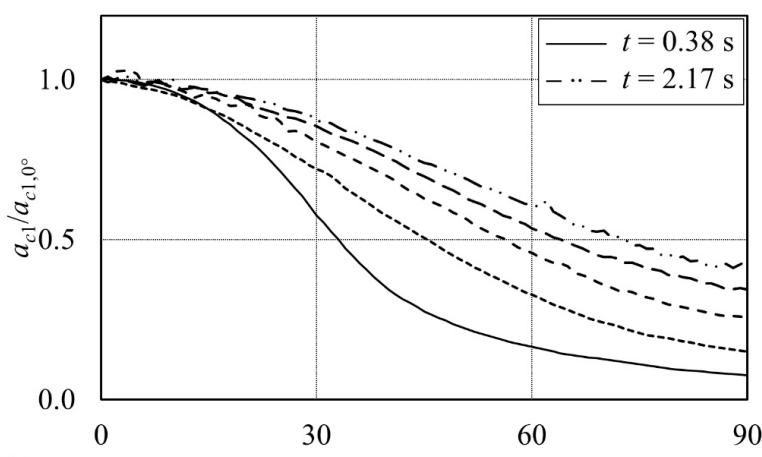

(b) $\gamma\left[^{\circ}\right]$

Fig. 10. First wave crest elevation profiles of Test 004 (Evers 2018) at $t=0.38 \mathrm{~s}, 0.83 \mathrm{~s}, 1.29 \mathrm{~s}, 1.75 \mathrm{~s}$, and $2.17 \mathrm{~s}$ for (a) $a_{c 1}$ and (b) $a_{c 1} / a_{c 1,0^{\circ}}$ versus $\gamma$

\section{Results}

\section{Slide impact zone}

The definition plots (Fig. 4 and Fig. 9) show the impact radius $r_{0}$. It represents the boundary between the slide impact zone and the wave propagation zone, defining the location at which impulse wave characteristics become first measurable. The relative impact radius is defined as $R_{0}=r_{0} / h$, varying for spatial wave propagation with the wave propagation angle $\gamma$. It is governed by the impulse product parameter $\mathrm{P}$, the relative slide width $B$, and the effective slide impact angle $\alpha_{\mathrm{eff}}=(6 / 7) \alpha$. For $\gamma=0^{\circ}$ and $90^{\circ}$ the measured values $R_{0}$ are approximated by

$$
\begin{aligned}
& R_{0,0^{\circ}}=r_{0,0^{\circ}} / h=2.5\left(\mathrm{P} B \cos \alpha_{\mathrm{eff}}\right)^{0.25} \\
& R_{0,90^{\circ}}=r_{0,90^{\circ}} / h=(B / 2)+1.5\left(\mathrm{P} \cos \alpha_{\mathrm{eff}}\right)^{0.25} .
\end{aligned}
$$

The cosine of $\alpha_{\text {eff }}$ is included twice, since it is also part of $\mathrm{P}$. As the center of the slide width represents the origin of $R_{0,90^{\circ}}$, its minimum value is $B / 2$ (Fig. $4 \mathrm{~b}$ ); i.e. very wide slides create large $R_{0,90^{\circ}}$ regardless the magnitude of the other slide parameters. For $\gamma$ between $0^{\circ}$ and $90^{\circ}, R_{0}$ is approximated by an ellipse in polar form as 
This material may be downloaded for personal use only. Any other use requires prior permission of the American Society of Civil Engineers. This material may be found at https://doi.org/10.1061/(ASCE)WW.1943-5460.0000514.

$$
R_{0}(\gamma)=\sqrt{\frac{R_{0,0^{\circ}}^{2} R_{0,90^{\circ}}^{2}}{R_{0,0^{\circ}}^{2} \sin ^{2} \gamma+R_{0,90^{\circ}}^{2} \cos ^{2} \gamma}} .
$$

The measured impact radii $R_{0, \text { meas }}$ for all $\gamma$ are plotted versus the predicted $R_{0, \text { pred }}$ in Fig. 11, including 65 of the total 74 experiments. For 9 experiments, the water surface close to slide impact location was not sufficiently captured by the videometric measurement system. Nonetheless, these experiments are still included in the results of the wave propagation zone. The coefficient of determination is $R^{2}=0.71$. For $R_{0}>3$, the predicted values tend to underestimate the measured values. However, most measured values scatter within a $\pm 30 \%$ range.
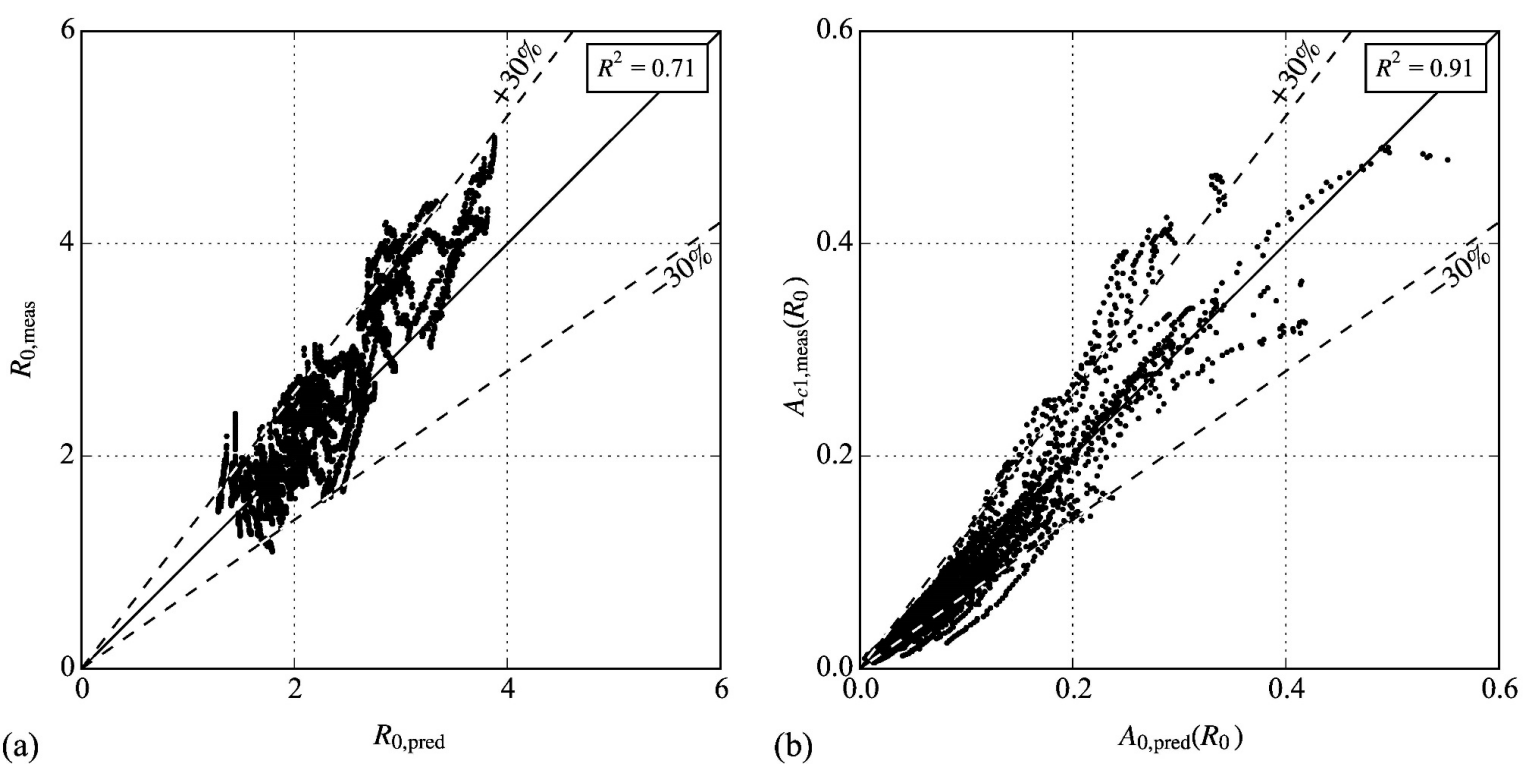

Fig. 11. (a) measured impact radii $R_{0 \text {,meas }}$ versus predicted $R_{0, \text { pred }}$ (Eq. 8) and (b) measured initial first wave crest amplitudes $A_{c 1 \text {,meas }}\left(R_{0}\right)$ versus predicted $A_{c 1, \text { pred }}\left(R_{0}\right)$ (Eq. 10)

The relative initial first wave crest amplitude $A_{0, c 1}$ represents the maximum wave crest elevation at $R_{0}$ for $\gamma=0^{\circ}$. It is governed by the impulse product parameter $\mathrm{P}$, the relative slide width $B$, and the effective slide impact angle $\alpha_{\mathrm{eff}}$ and is approximated with

$$
A_{0, c 1}=a_{0, c 1} / h=0.2 \mathrm{P}^{0.5} B^{0.75}\left(\cos \alpha_{\mathrm{eff}}\right)^{0.25} .
$$

For $\gamma$ between $0^{\circ}$ and $90^{\circ}$, the relative first wave crest amplitude $A_{\mathrm{c} 1}$ at $R_{0}$ follows

$$
A_{c 1}\left(R_{0}\right)=A_{0, c 1}\left[\operatorname{sech}\left(3.2 \frac{\gamma}{90^{\circ}}\right)\right]^{\cos \alpha_{\mathrm{eff}}} .
$$

The hyperbolic secant function describes the initial wave crest shape over $\gamma$. This function features an inflection point, which may also be observed in the measurements as shown in Fig. 10(a). The effect of $\alpha$ on the initial wave crest shape is accounted for by the exponent. While the ratio of $A_{c 1}\left(R_{0,0^{\circ}}\right)$ to $A_{c 1}\left(R_{0,90^{\circ}}\right)$ is $\cong 1.75$ for the vertical impact $\left(\alpha=90^{\circ}\right)$, it increases to approximately 9.6 for $\alpha=30^{\circ}$. The measured initial first wave amplitudes $A_{c 1 \text {,meas }}$ at $R_{0}$ for all $\gamma$ of the 65 experiments are plotted versus the predicted $A_{c 1 \text {,pred }}$ in Fig. $11\left(R^{2}=0.91\right)$.

\section{Wave propagation zone}

The following wave characteristics were tracked and analyzed in the wave propagation zone: first wave crest amplitude $a_{c 1}$, first wave trough amplitude $a_{t 1}$, second wave crest amplitude $a_{c 2}$, first wave height $H_{1}$, first wave period $T_{1}$, as well as the first and the second wave celerities $c_{c 1}$ and $c_{c 2}$ (Fig. 4). These wave characteristics allow for assessing the magnitude and consequently the impact of the outgoing wave train front at a specific location relative to the wave source. 
This material may be downloaded for personal use only. Any other use requires prior permission of the American Society of Civil Engineers. This material may be found at https://doi.org/10.1061/(ASCE)WW.1943-5460.0000514.

The definition plots (Fig. 4 and Fig. 9) show the surrogate radial wave propagation distance $r^{*}$. It extends the impact radius $r_{0}$ and is the radial coordinate for describing the wave characteristics in the wave propagation zone, i.e. outside the slide impact zone. The relative wave propagation distance $r / h$ is defined as the sum of the relative impact radius $R_{0}$ and the relative surrogate radial wave propagation distance $R^{*}$

$$
r / h=r_{0} / h+r^{*} / h=R_{0}+R^{*}
$$

The crest elevation above the stillwater surface of the first outgoing wave is defined as the first wave crest amplitude $a_{c 1}$ (Fig. 4). The measured relative first wave crest amplitudes $A_{c 1}=a_{c 1} / h$ for all $\gamma$ are approximated by

$$
A_{c 1}\left(R^{*}, \gamma\right)=A_{0, c 1} \exp \left(-0.4 A_{0, c 1}^{-0.3} \sqrt{R^{*}}\right)\left[\operatorname{sech}\left(3.2 \frac{\gamma}{90^{\circ}}\right)\right]^{\cos \alpha_{\mathrm{eff}} \exp \left(-0.15 \sqrt{R^{*}}\right)}
$$

Eq. (12) extends Eq. (10) by including $R^{*}$ to describe the wave decay effect. The first exp-function accounts for the amplitude decay in the propagation direction $\gamma=0^{\circ}$. The second exp-function in the exponent of the hyperbolic secant function includes the effect of lateral wave crest spreading, i.e. the decreasing ratio of the amplitudes at $\gamma=0^{\circ}$ to $90^{\circ}$ during wave propagation as shown in Fig. 10. Fig. 12 shows a histogram with the distribution of the measured wave amplitudes versus those predicted. In total, $n=208,685$ data points were extracted in $1^{\circ}$ steps between $\gamma=0^{\circ}$ and $90^{\circ}$ from the interpolated water surface measurements and included into the analysis. The horizontal axis shows the relative deviation of the measured values from the predicted as

$$
\Delta_{\text {meas }}(\text { variable })=1-\left(\frac{\text { measured value }}{\text { predicted value }}\right)
$$

Therefore, $A_{c 1 \text {,meas }} / A_{c 1 \text {,pred }}=1$ represents $0 \%$ deviation. In the box plot of Fig. 12, the first and the third quartiles are represented by the box. The band inside the box is the median. The whiskers depict the $5^{\text {th }}$ and the $95^{\text {th }}$ percentiles, i.e. $90 \%$ of the measured data scatter within a range of $-45 \%$ and $+25 \%$ around Eq. (12). The coefficient of determination is $R^{2}=0.89$.
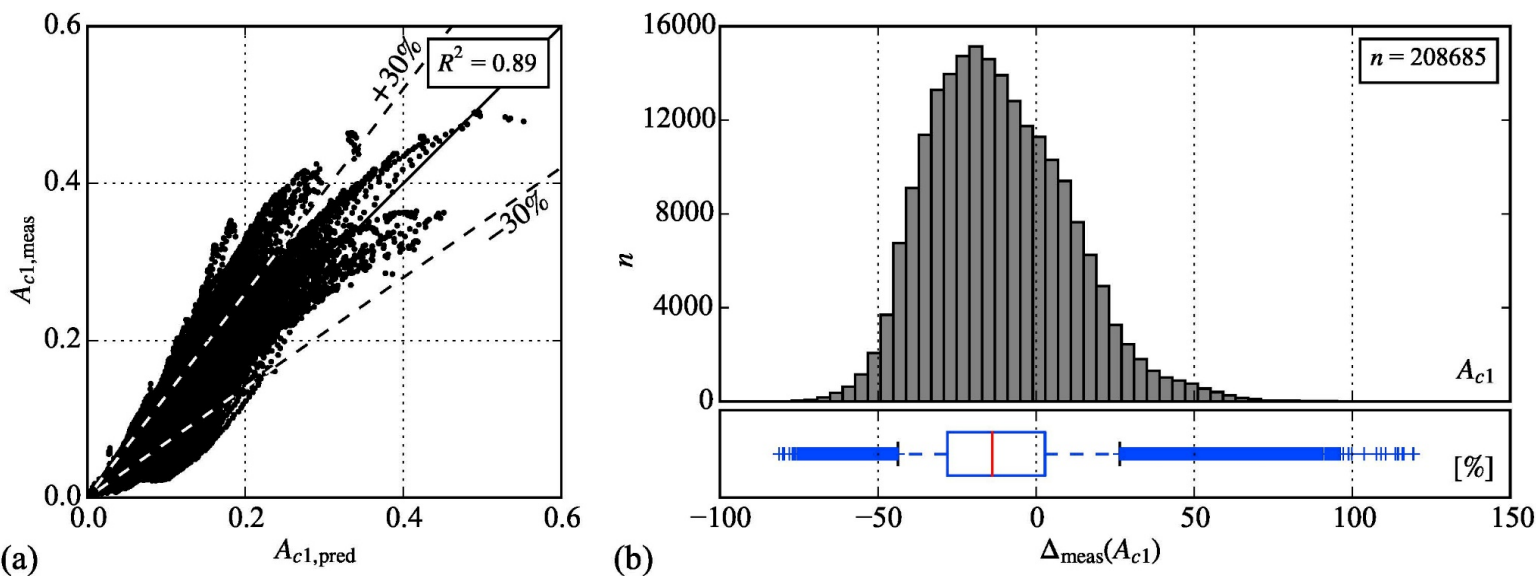

Fig. 12. (a) Scatter plot of measured relative first wave crest amplitudes $A_{c 1 \text {,meas }}$ versus predicted $A_{c 1 \text {,pred }}$ (Eq. 12), (b) histogram, and box plot with whiskers at $5^{\text {th }}$ and $95^{\text {th }}$ percentiles of $\Delta_{\text {meas }}\left(A_{c 1}\right)$

In Fig. 13 the box plots are subdivided according to the relative wave propagation distance $r / h$ and the wave propagation angle $\gamma$, respectively. Again, $0 \%$ represents perfect agreement between predicted and measured values. The scatter is largest for $r / h$ between 1.5 and 9 . However, note that most of the measured data are in that parameter range. The amplitudes for $\gamma>60^{\circ}$ are slightly more overestimated by Eq. (12), while the scatter is increasing. 

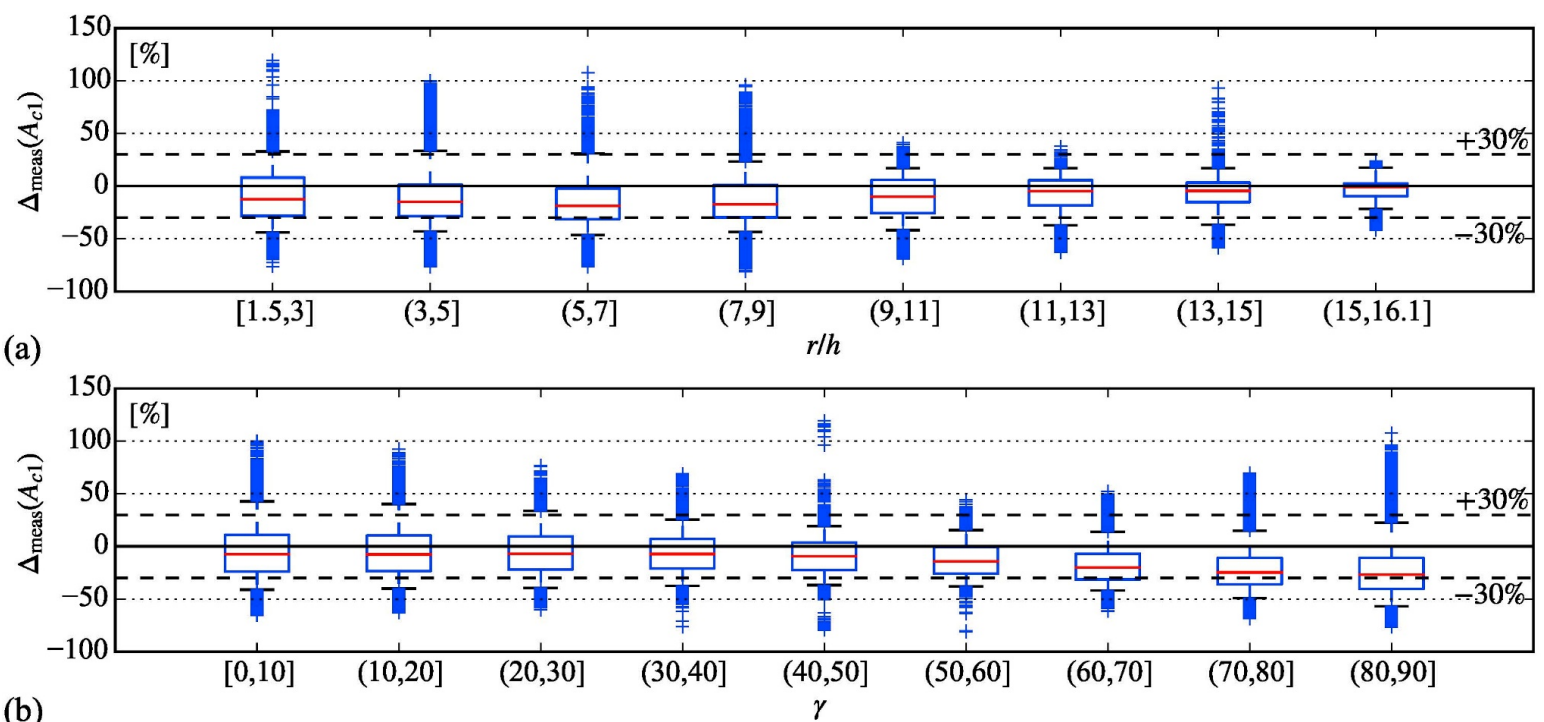

Fig. 13. Box plots with whiskers at $5^{\text {th }}$ and $95^{\text {th }}$ percentiles for $\Delta_{\text {meas }}\left(A_{c 1}\right)$ versus (a) relative propagation distance $r / h$ and (b) wave propagation angle $\gamma$

The depression below the stillwater surface following $a_{c 1}$ is defined as the first wave trough amplitude $a_{t 1}$ (Fig. 4). Its relative value $A_{0, t 1}$ at $R_{0}$ and $\gamma=0^{\circ}$ follows

$$
A_{0, t 1}=a_{0, t 1} / h=0.35\left(\mathrm{P} B \cos \alpha_{\mathrm{eff}}\right)^{0.5} .
$$

The measured relative first wave trough amplitude $A_{t 1}=a_{t 1} / h$ are approximated by

$$
A_{t 1}\left(R^{*}, \gamma\right)=A_{0, t 1} \exp \left(-0.4 A_{0, t 1}^{-0.3} \sqrt{R^{*}}\right)\left[\operatorname{sech}\left(3.6 \frac{\gamma}{90^{\circ}}\right)\right]^{\cos \alpha_{\mathrm{eff}} \exp \left(-0.15 \sqrt{R^{*}}\right)}
$$

A total of $90 \%$ of the measured data in Fig. 14 scatter between $-20 \%$ and $+40 \%$. The coefficient of determination is $R^{2}=0.91$. As shown in Fig. 15, the underestimation is highest close to the impact location and slightly increases for $r / h>7$. Furthermore, the measured values are slightly underestimated for $\gamma$ between $20^{\circ}$ and $80^{\circ}$.

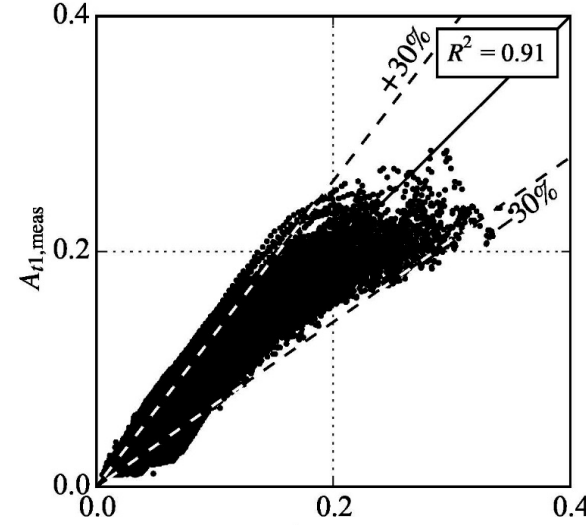

(a)

$A_{t 1, \text { pred }}$

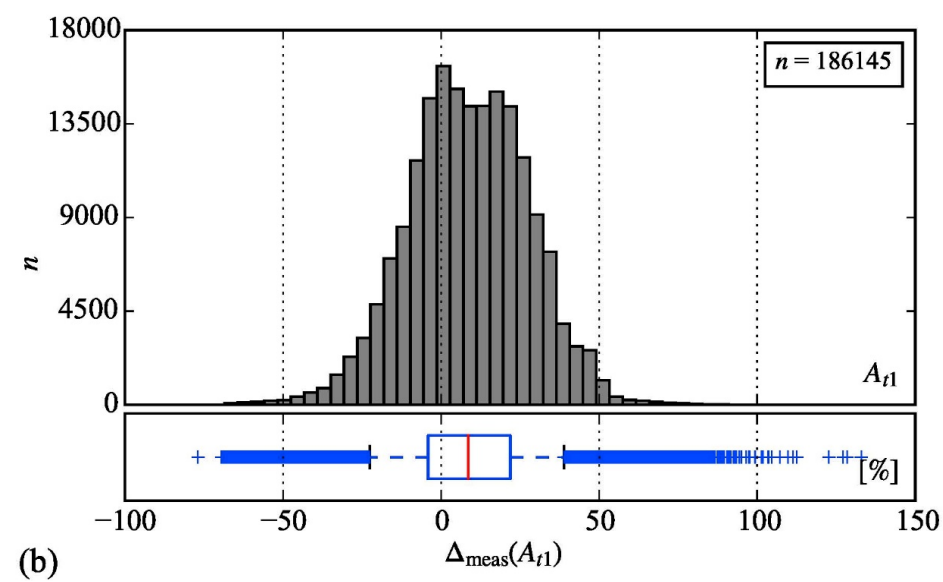

(b)

Fig. 14. (a) Scatter plot of measured relative first wave trough amplitudes $A_{t 1, \text { meas }}$ versus predicted $A_{t 1, \text { pred }}$ (Eq. 15), (b) histogram, and box plot with whiskers at $5^{\text {th }}$ and $95^{\text {th }}$ percentiles of $\Delta_{\text {meas }}\left(A_{t 1}\right)$ 

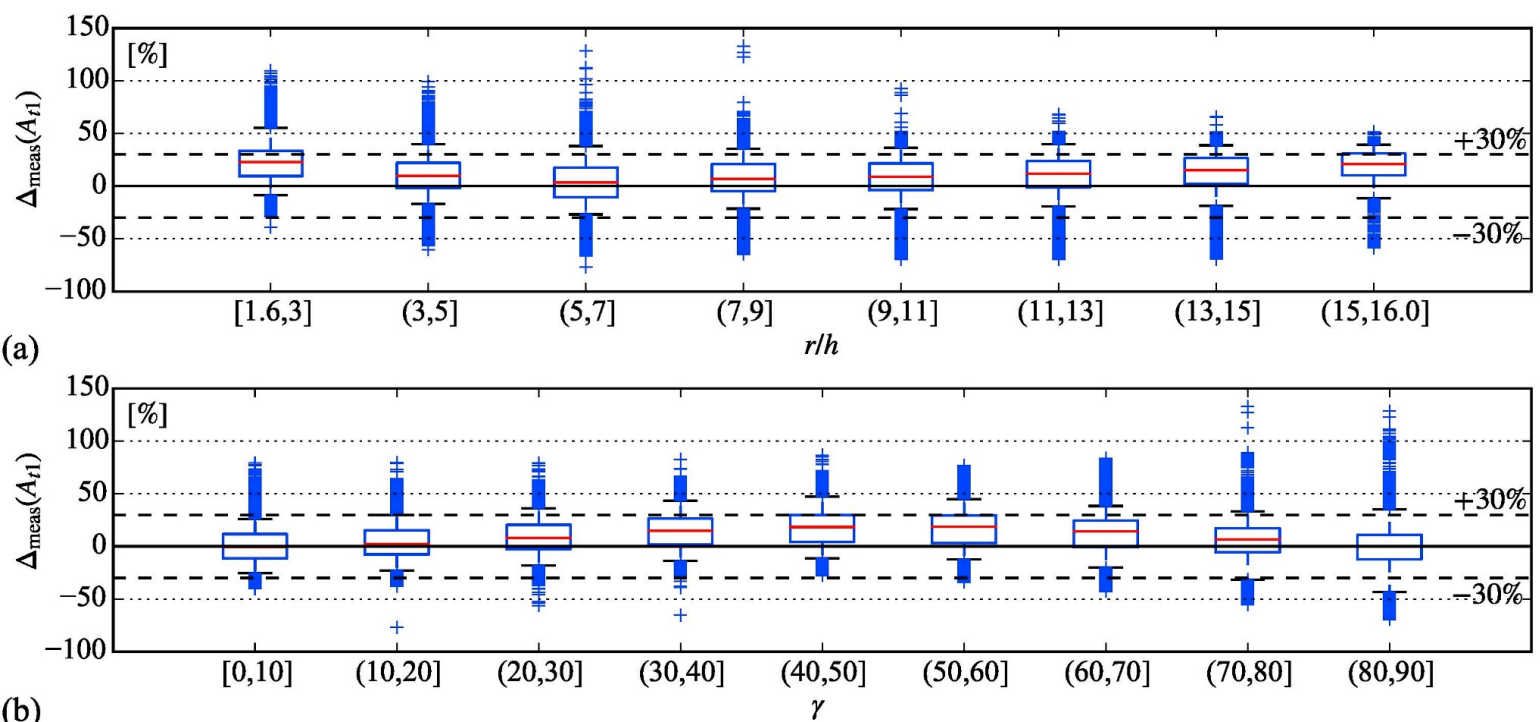

Fig. 15. Box plots with whiskers at $5^{\text {th }}$ and $95^{\text {th }}$ percentiles for $\Delta_{\text {meas }}\left(A_{t 1}\right)$ versus (a) relative propagation distance $r / h$ and (b) wave propagation angle $\gamma$

The second wave crest amplitude $a_{c 2}$ is defined as the crest elevation above the water surface of the second outgoing wave (Fig. 4). The relative initial second wave crest amplitude $A_{0, c 2}$ at $R_{0}$ and $\gamma=0^{\circ}$ is approximated by

$$
A_{0, c 2}=a_{0, c 2} / h=0.14\left(\mathrm{P} B \cos \alpha_{\mathrm{eff}}\right)^{0.25} .
$$

The measured relative second wave crest amplitudes $A_{c 2}=a_{c 2} / h$ for all $\gamma$ are approximated by

$$
A_{c 2}\left(R^{*}, \gamma\right)=A_{0, c 2} \exp \left(-0.1 A_{0, c 2}^{-0.3} \sqrt{R^{*}}\right)\left[\operatorname{sech}\left(3 \frac{\gamma}{90^{\circ}}\right)\right]^{\cos \alpha_{\text {eff }} \exp \left(-0.15 \sqrt{R^{*}}\right)} .
$$

Fig. 16 shows measured values for $A_{c 2}$. Compared to $A_{c 1}$ (Eq. 12), the scatter is substantially larger with $90 \%$ of the data points within $-60 \%$ and $+50 \%\left(R^{2}=0.69\right)$. The largest scatter occurs for $r / h<5$, i.e. close to the slide impact location (Fig. 16).
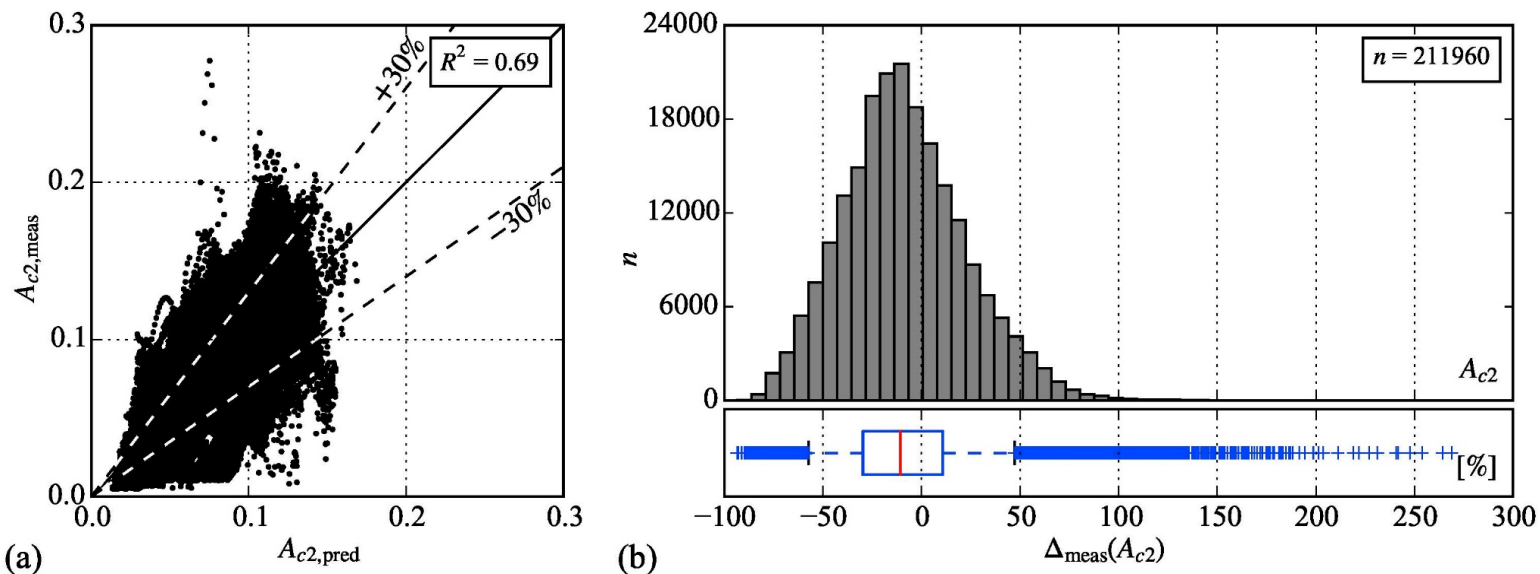

Fig. 16. (a) Scatter plot of measured relative second wave crest amplitudes $A_{c 2 \text {,meas }}$ versus predicted $A_{c 2 \text {,pred }}$ (Eq. 17), (b) histogram, and box plot with whiskers at $5^{\text {th }}$ and $95^{\text {th }}$ percentiles of $\Delta_{\text {meas }}\left(A_{c 2}\right)$ 

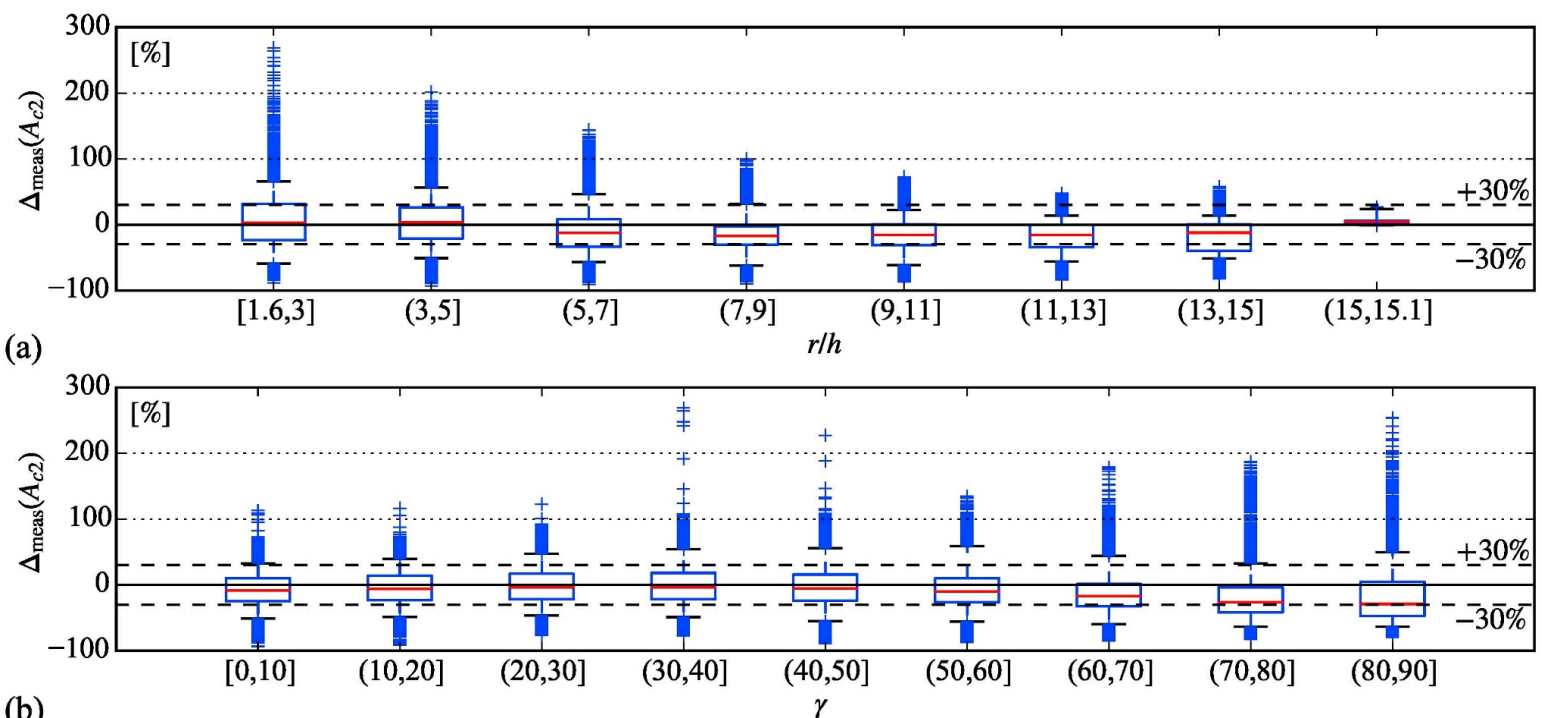

(b)

Fig. 17. Box plots with whiskers at $5^{\text {th }}$ and $95^{\text {th }}$ percentiles of $\Delta_{\text {meas }}\left(A_{c 2}\right)$ versus (a) relative propagation distance $r / h$ and (b) wave propagation angle $\gamma$ The first wave height $H_{1}$ is defined as the distance between the water surface elevation of the first wave crest and trough amplitudes at the same location (Fig. 4). The measured relative values $Y_{1}=H_{1} / h$ are therefore given as

$$
Y_{1}\left(R^{*}, \gamma\right)=A_{c 1}+A_{t 1}
$$

$90 \%$ of the data in Fig. 18 scatter evenly between $-30 \%$ and $+25 \%$ with the median close to zero $\left(R^{2}=0.93\right)$.

The first wave period $T_{1}$ is defined as the time difference between the initial uplifting of the first wave crest and the stillwater level intersection following the first wave trough at the same location (Fig. 4). The initial uplifting was tracked at the location where the water level exceeded an absolute threshold equal to the estimated measurement accuracy of $1 \mathrm{~mm}$ above the stillwater level. The measured relative first wave periods $T_{1}(g / h)^{0.5}$ are approximated by

$$
T_{1}\left(R^{*}, \gamma\right)(g / h)^{0.5}=10\left(Y_{1}\right)^{0.2}+\left(R^{*} / 2\right)
$$

The data in Fig. 19 has a narrow scatter range with $90 \%$ between $-10 \%$ and $+15 \%\left(R^{2}=0.86\right) . T_{1}(g / h)^{0.5}$ only depends on the relative wave height $Y_{1}$ and the relative surrogate radial wave propagation distance $R^{*}$.

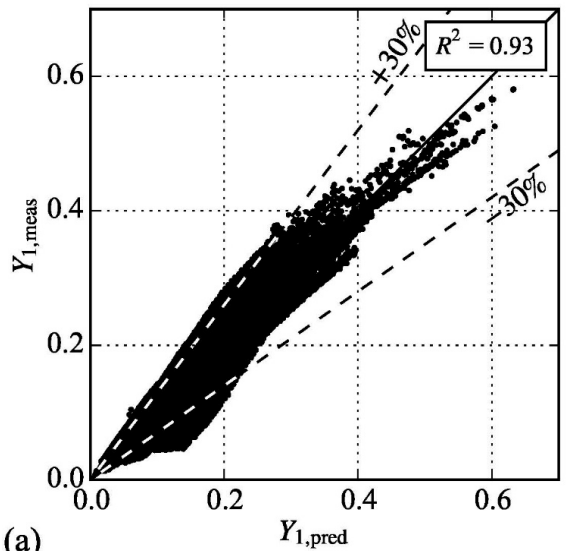

(a)

Fig. 18. (a) Scatter plot of measured relative first wave heights $Y_{1, \text { meas }}$ versus predicted $Y_{1, \text { pred }}$ (Eq. 18), (b) histogram and box plot with whiskers at $5^{\text {th }}$ and $95^{\text {th }}$ percentiles of $\Delta_{\text {meas }}\left(Y_{1}\right)$

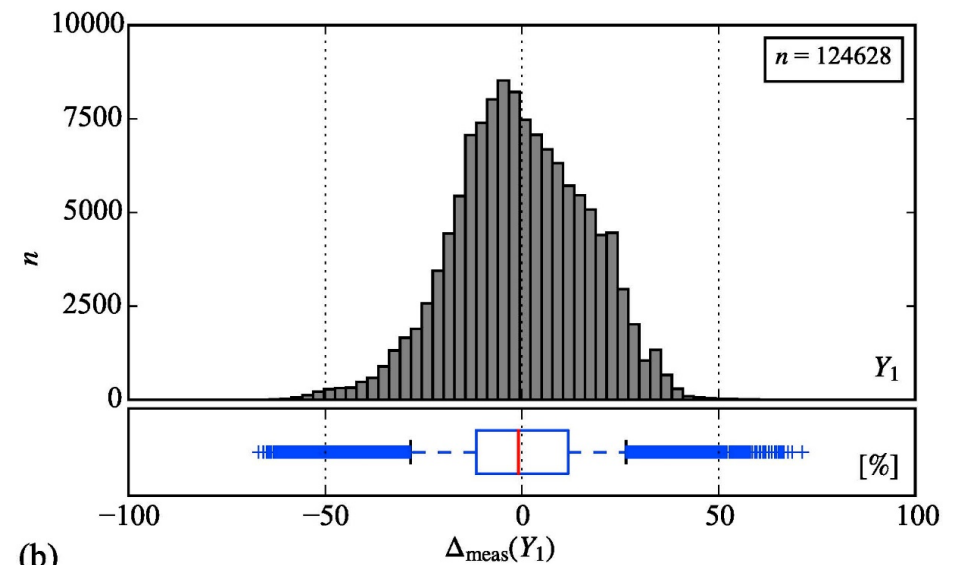

(b) 


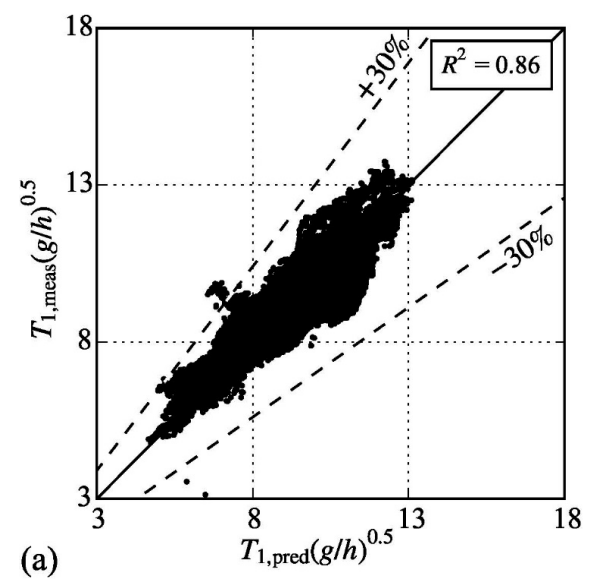

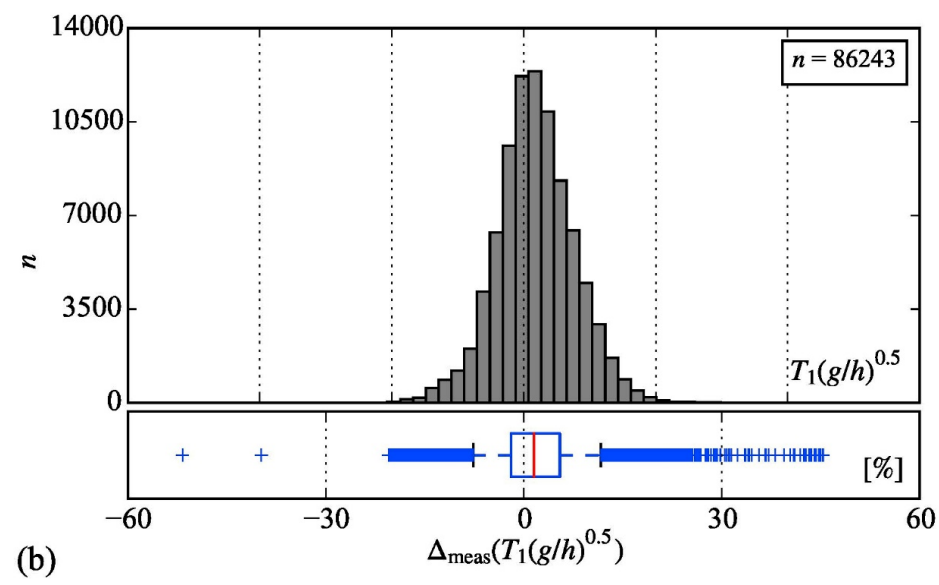

(b)

Fig. 19. (a) Scatter plot of measured relative first wave period $T_{1, \text { meas }}(g / h)^{0.5}$ versus predicted $T_{1, \text { pred }}(g / h)^{0.5}$ (Eq. 19), (b) histogram and box plot with whiskers at $5^{\text {th }}$ and $95^{\text {th }}$ percentiles of $\Delta_{\text {meas }}\left(T_{1}(g / h)^{0.5}\right)$

The first and the second wave celerities $c_{c 1}$ and $c_{c 2}$ are defined as the propagation celerities of the first and second wave crests, respectively. The measured relative first wave celerities $c_{c 1} /(g h)^{0.5}$ are approximated by

$$
c_{c 1} /(g h)^{0.5}=0.95\left(1+A_{c 1}\right)^{0.5} .
$$

The data scatter with $90 \%$ between $-15 \%$ and $+10 \%\left(R^{2}=-0.06\right.$, Fig. 20$)$. The measured relative second wave celerities $c_{c 2} /(g h)^{0.5}$ are approximated by

$$
c_{c 2} /(g h)^{0.5}=0.7\left(1+A_{c 2}\right)^{0.5} .
$$

The data scatter with $90 \%$ between $-25 \%$ and $+15 \%\left(R^{2}=-0.03\right.$, Fig. 21$)$. The negative values of $R^{2}$ arise from the missing intercept in Eqs. (20) and (21). The measured values deviate acceptably from these predicted.
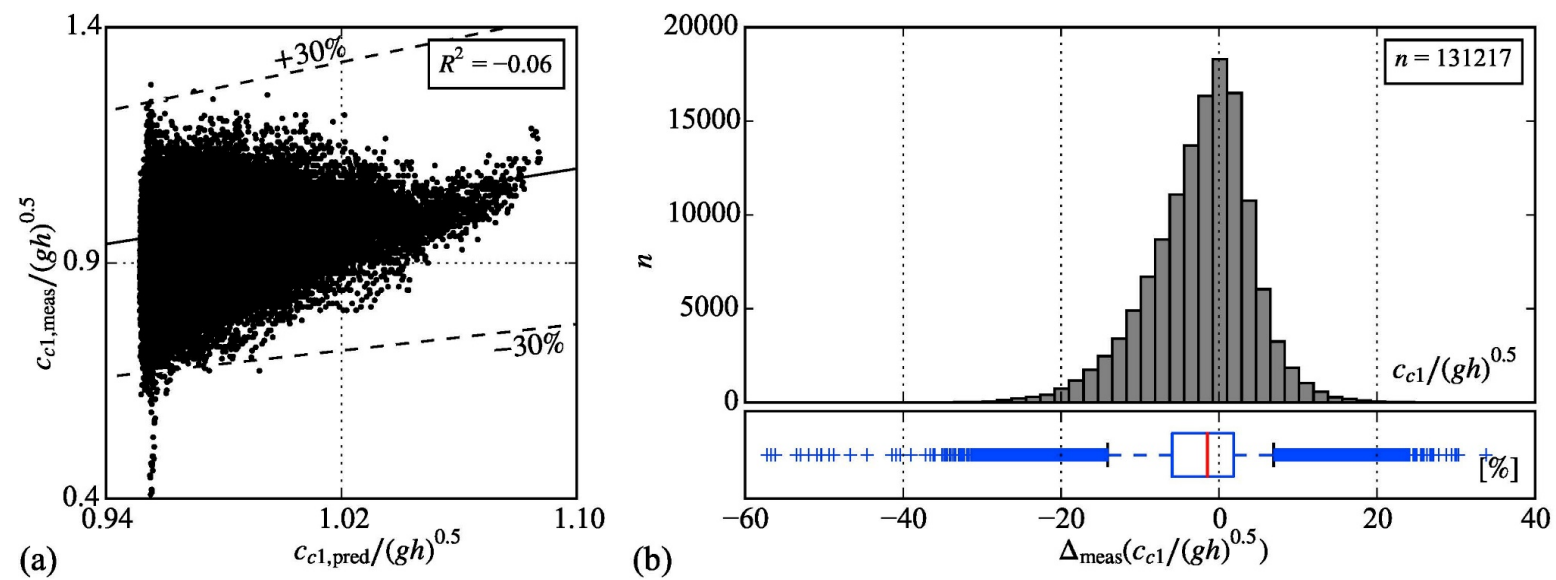

Fig. 20. (a) Scatter plot of measured relative first wave crest celerity $c_{c 1, \text { meas }} /(g h)^{0.5}$ versus predicted $c_{c 1, \text { pred }} /(g h)^{0.5}$ (Eq. 20), (b) histogram and box plot with whiskers at $5^{\text {th }}$ and $95^{\text {th }}$ percentiles of $\Delta_{\text {meas }}\left(c_{c 1} /(g h)^{0.5}\right)$ 

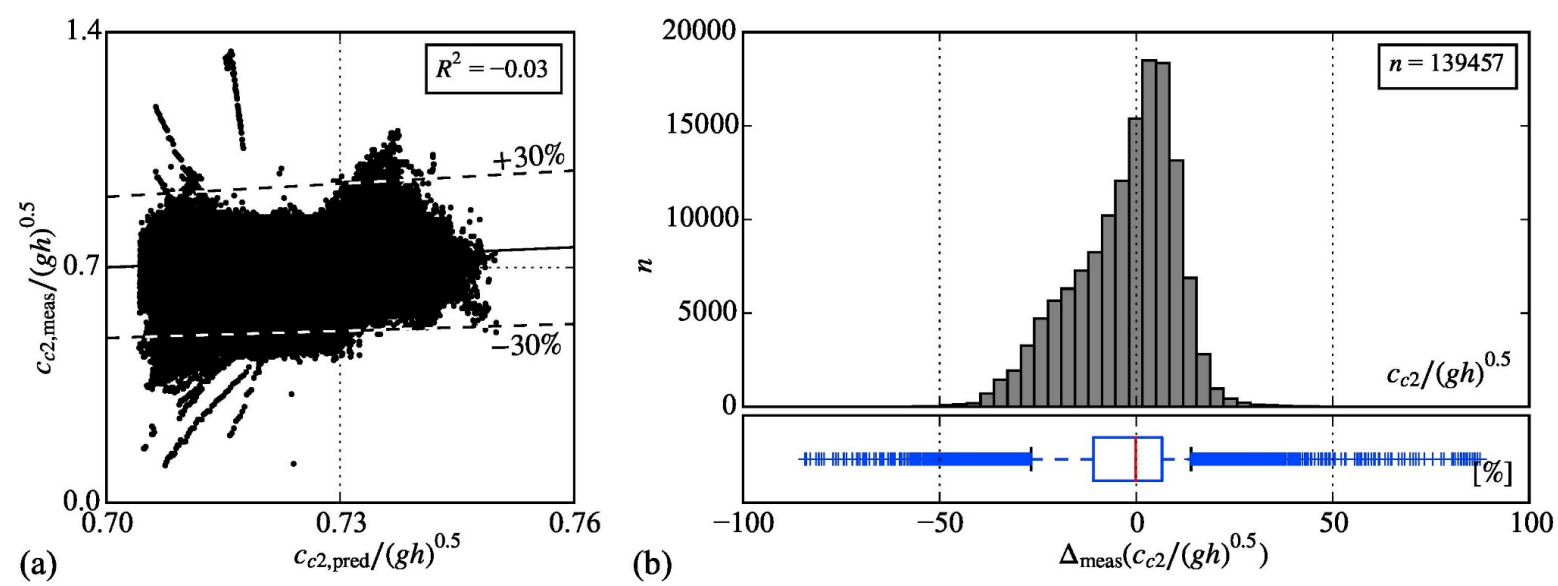

Fig. 21. (a) Scatter plot of measured relative second wave crest celerity $c_{c 2, \text { meas }} /(g h)^{0.5}$ versus predicted $c_{c 2, \text { pred }} /(g h)^{0.5}$ (Eq. 21), (b) histogram and box plot with whiskers at $5^{\text {th }}$ and $95^{\text {th }}$ percentiles of $\Delta_{\text {meas }}\left(c_{c 2} /(g h)^{0.5}\right)$

\section{Discussion}

The governing parameters given in Table 1 represent the limitations of the empirical equations proposed in the preceding section. The slide impact velocities $V_{s}$ cover a range both below and above the shallow water wave celerity $(g h)^{0.5}$, i.e. $\mathrm{F}<1$ and $\mathrm{F}>1$. Although the slide mass $m_{s}$ was varied in the experiments, the bulk slide density $\rho_{s}=1,338 \mathrm{~kg} / \mathrm{m}^{3}$ remained constant. However, all equations include the impulse product parameter $\mathrm{P}$, representing the momentum transfer per unit slide width, derived from 2D experiments with $\rho_{s}$ between $590 \mathrm{~kg} / \mathrm{m}^{3}$ and $1720 \mathrm{~kg} / \mathrm{m}^{3}$ (Heller and Hager 2010). Therefore, the application range of the equations presented may be potentially extended to bulk slide densities lower than the water density although these were not covered in the present experiments. The limitations of the wave propagation angle $\gamma$ have to be assessed based on the geometry of the waterbody. While Mohammed and Fritz (2012) studied the edge wave propagation at a straight beach extending the sliding plane, McFall and Fritz $(2016,2017)$ also included edge waves on the curvilinear shoreline of a conical island. At Chehalis Lake, these edge waves had a lower but nonetheless significant runup compared to the waves for $\gamma=0^{\circ}$ (Roberts et al. 2013). The experimental setup of this study resembles the tip of a headland, since it is not bounded by an inclined shoreline, and edge waves were not accounted for. Heller et al. (2012) conducted experiments in a wave basin with confining side walls, adjusted to a basin side angle $\theta$. For $\theta$ between $30^{\circ}$ and $90^{\circ}$, with $\theta=0^{\circ}$ representing a 2D flume, no significant effect on the maximum wave features was found at $\gamma=0^{\circ}$. Edge waves strongly depend on the bathymetry and topography of the water body and require a case-bycase assessment. The maximum relative wave propagation distance reached in the experiments was $r / h \approx 16$. While this upper limitation of the propagation distance is not sufficient to cover long distances in oceans, it is suitable for smaller confined basins, e.g. bays or fjords. The lower limit of $r / h$ is directly defined by the impact radius $R_{0}$. The approach by Heller et al. (2009) states $r / h=5$ as global lower limit. Therefore, the present approach involving $R_{0}$ allows for the prediction of impulse wave characteristics closer to the impact location (Fig. 11).

Eqs. (9), (14), and (16) describe the initial wave amplitudes at the impact radius $R_{0}$ for $\gamma=0^{\circ}$. Parameter $\mathrm{P}$, introduced by Heller and Hager (2010) based on 2D experiments, is included in all three equations. The results of this study indicate that $\mathrm{P}$ is also applicable to the generation and propagation of impulse waves in 3D. However, the relative slide width $B$ has to be included as an additional parameter, since $\mathbf{P}$ solely accounts for the unit momentum transfer from the slide to the water column. The effective slide impact angle $\alpha_{\text {eff }}$ is also added as an additional parameter. Although it is already included in $\mathrm{P}$, it has a strong influence in spatial environments. The features of 3D impulse waves therefore are based on these of 2D impulse waves and extended by typical 3D wave parameters as previously described. 


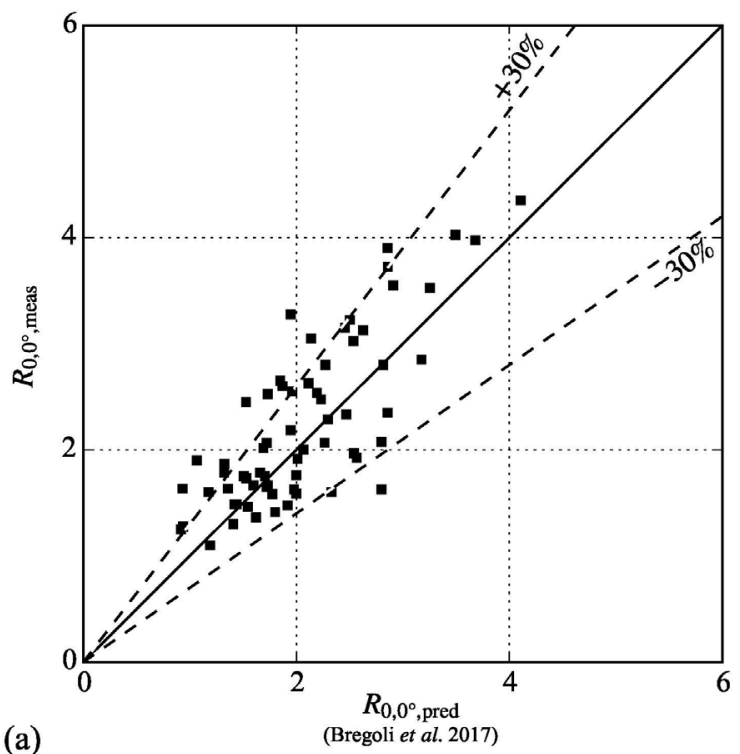

(a) $R_{0,0^{\circ} \text {,pred }}$
(Bregoli et al. 2017)

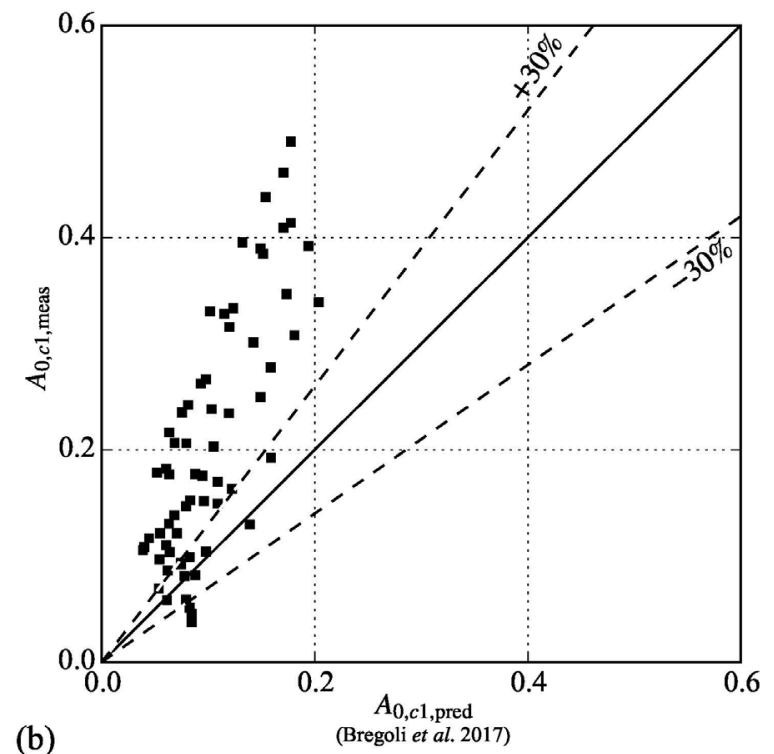

(b)

Fig. 22. (a) Measured impact radii $R_{0,0^{\circ}, \text { meas }}$ versus predicted $R_{0,0^{\circ}, \text { pred }}$ (Eq. 23) and (b) measured initial first wave crest amplitudes $A_{0, c 1, \text { meas }}$ versus predicted $A_{0, c 1, \text { pred }}$ (Eq. 22); values predicted with equations by Bregoli et al. (2017)

Bregoli et al. (2017) proposed for the maximum wave amplitude $a_{\max }$ and its distance $x_{\max }$ from the impact location

$$
\begin{aligned}
& a_{\max } / h=0.118(S)^{0.459}\left(\frac{l_{s}}{h}\right)^{0.463} \mathrm{~F}^{0.554} \hat{=} A_{0, c 1} \\
& x_{\max } / h=3.97(S)^{0.198}\left(\frac{m_{s} V_{s}^{2}}{\rho_{w} g b l_{s} h^{2}}\right)^{0.277} \hat{=} R_{0,0^{\circ}} .
\end{aligned}
$$

Eqs (22) and (23) correspond to the relative initial wave amplitude $A_{0, c 1}$ (Eq. 9) and the relative impact radius $R_{0,0^{\circ}}$ (Eq. 6) for a single wave propagation angle $\gamma=0^{\circ}$, respectively. In Fig. 22, Eqs (22) and (23) by Bregoli et al. (2017) are applied to predict the dataset of this study. The slide length is substituted with $l_{s}=m_{s} / s b \rho_{s}$. While the measured relative impact radii $R_{0,0^{\circ}}$ for $\gamma=0^{\circ}$ are in good agreement with the prediction, the predicted relative initial wave amplitudes $A_{0, c 1}$ are largely underestimating the measured values. Compared to $R_{0,0^{\circ}}$, the equation for $x_{\max } / h$ by Bregoli et al. (2017) does not include the effect of the slide impact angle $\alpha$. While Kamphuis and Bowering (1970) found an only minor effect of $\alpha$ on the generated wave magnitudes, Heller and Hager (2010) included its effect into the impulse product parameter P. In addition, the equation for $a_{\max } / h$ does not include the effect of the slide mass $m_{s}$, the slide width $b$, and again $\alpha$, which may explain the observed deviations.

Eqs. (12), (15), and (17) include the initial amplitudes describing the spatial wave propagation process with the relative surrogate wave propagation radius $R^{*}$ and the wave propagation angle $\gamma$ as polar coordinates. $R^{*}=0$ is equivalent to the impact radius $R_{0}$ and the equations are defined for $R^{*} \geq 0$. The wave amplitude decay processes are described by exponential functions, also contained in Hughes (1993) for different wave attenuation equations as well as by Bregoli et al. (2017) in their relations describing impulse wave propagation for $\gamma=0^{\circ}$. While the exponential function in Eq. (12) includes a factor of -0.4 , Eq. (17) has a lower factor of -0.1 , indicating that $a_{c 2}$ is subject to a smaller wave decay rate than $a_{c 1}$. However, the initial first wave crest amplitude $A_{0, c 1}$ (Eq. 9) is generally larger than the second $A_{0, c 2}$ (Eq. 16). In combination with the different decay rates, the ratio of $A_{c 1}$ to $A_{c 2}$ is subject to permanent variation during propagation. To describe the wave crest and trough shapes along $\gamma$, hyperbolic secant functions were selected based on experimental observations (Fig. 10). Their exponents include $\alpha_{\text {eff }}$ and $R^{*}$ as governing parameters accounting for the lateral spreading during wave propagation. A slightly different exponent to describe this effect was originally introduced by Heller et al. (2015). 
This material may be downloaded for personal use only. Any other use requires prior permission of the American Society of Civil Engineers. This material may be found at https://doi.org/10.1061/(ASCE)WW.1943-5460.0000514.

In the context of hazard assessment, the predicted wave characteristics act as input parameters to estimate the impact at the shoreline. Besides wave crest amplitudes, also the wave height, the wave period, and the wave length are accounted for, e.g. by Müller (1995). Among various water wave types (Heller 2008), the solitary wave causes runup heights with the highest elevation (Synolakis 1989). Impulse waves exhibit features of wave types within the range of intermediate-water to shallow-water waves depending on the generation process (Fritz et al. 2004, Heller and Hager 2011). The measured wave crest celerities of this study are presented in relation to solitary waves (Eqs. 20 and 21). While the first wave crest propagates at approximately $95 \%$ of the solitary wave celerity, the second wave crest reaches $70 \%$. The celerity reduction from the first to the second wave crest is on average $26 \%$. This is a slightly higher reduction than $18 \%$ to $23 \%$ observed by Mohammed and Fritz (2012) and 23\% by McFall and Fritz (2016).

The videometric measurement system allows for a quasi-continuous representation of the water surface and consequently a high number of data points. This measurement technique allowed for adaptively tracking the newly introduced impact radius $r_{0}$. Another advantage of the high number of data points is highlighted by the box plots in Fig. 13, Fig. 15, and Fig. 17. These plots allow for assessing the evolution of the impulse wave features as well as their respective scatter along the polar coordinates $r / h$ and $\gamma$.

\section{Conclusions}

Impulse waves were generated in a hydraulic laboratory wave basin and their spatial propagation patterns tracked with a videometric measurement system. The following wave features were extracted from the water surface contours: the amplitudes of the first wave crest and trough as well as the second wave crest, the height and period of the first wave, and the celerities of the first and the second wave crest. Empirical dimensionless equations are proposed to predict the magnitude of these wave features based on the slide impact velocity, the slide mass, the slide thickness, the slide width, the slide impact angle, and the stillwater depth as governing parameters. The main findings are:

- The impulse product parameter, originally derived from 2D wave flume experiments, in combination with the slide width and the additional effect of the slide impact angle, is suitable to quantify the spatial impulse wave generation and propagation features.

- The impact zone close to the slide impact location is influenced by the collapse of the impact crater, strong turbulence, and arbitrary distortion of the water surface, while in the wave propagation zone, distinct characteristics of the outgoing wave train, e.g. amplitudes, become quantifiable.

- The transition from the impact zone to the wave propagation zone is confined by the impact radius $r_{0}$, which is governed by the slide characteristics; the spatial extent of $r_{0}$ is approximated by an ellipse.

- The crest and trough shapes of the spatially propagating wave train is approximated by a hyperbolic secant function featuring an exponent accounting for the lateral spreading of the wave crest during propagation.

- The wave decay is approximated by an exponential function; the first wave crest amplitude is thereby subject to a higher wave decay rate than the second wave crest amplitude.

- While the first wave crest propagates at $95 \%$ of the solitary wave celerity, the second does at only $70 \%$.

The equations derived in this study allow for predicting impulse wave magnitudes at a specific location relative to the wave source based on the governing slide parameters. In combination with equations from literature describing the wave impact, e.g. runup heights, a preliminary hazard assessment for potential landslide generated impulse wave events at prototype scale may be conducted.

\section{Acknowledgments}

This work was supported by the Swiss National Science Foundation (Project No. 200021-143657) and is part of the Swiss Competence Center for Energy Research - Supply of Electricity (SCCER-SoE). 
This material may be downloaded for personal use only. Any other use requires prior permission of the American Society of Civil Engineers. This material may be found at https://doi.org/10.1061/(ASCE)WW.1943-5460.0000514.

\section{Notation}

\begin{tabular}{|c|c|}
\hline$A_{0, c 1}$ & Relative initial first wave crest amplitude for $\gamma=0^{\circ}[-]$ \\
\hline$a_{0, c 1}$ & Initial first wave crest amplitude for $\gamma=0^{\circ}[\mathrm{m}]$ \\
\hline$A_{0, c 2}$ & Relative initial second wave crest amplitude for $\gamma=0^{\circ}[-]$ \\
\hline$a_{0, c 2}$ & Initial second wave crest amplitude for $\gamma=0^{\circ}[\mathrm{m}]$ \\
\hline$A_{0, t 1}$ & Relative initial first wave trough amplitude for $\gamma=0^{\circ}[-]$ \\
\hline$a_{0, t 1}$ & First wave trough amplitude for $\gamma=0^{\circ}[\mathrm{m}]$ \\
\hline$A_{c 1}$ & Relative first wave crest amplitude [-] \\
\hline$a_{c 1}$ & First wave crest amplitude $[\mathrm{m}]$ \\
\hline$A_{c 2}$ & Relative second wave crest amplitude [-] \\
\hline$a_{c 2}$ & Second wave crest amplitude $[\mathrm{m}]$ \\
\hline$a_{\max }$ & Maximum wave amplitude for $\gamma=0^{\circ}$ by Bregoli et al. (2017) [m] \\
\hline$A_{t 1}$ & Relative first wave trough amplitude [-] \\
\hline$a_{t 1}$ & First wave trough amplitude $[\mathrm{m}]$ \\
\hline$b$ & Slide width $[\mathrm{m}]$ \\
\hline$c_{c 1}$ & First wave crest celerity $\left[\mathrm{m} \mathrm{s}^{-1}\right]$ \\
\hline$c_{c 2}$ & Second wave crest celerity $\left[\mathrm{m} \mathrm{s}^{-1}\right]$ \\
\hline$d_{g}$ & Grain diameter $[\mathrm{mm}]$ \\
\hline $\mathrm{F}$ & Slide Froude number [-] \\
\hline$g$ & Gravitational acceleration $\left[\mathrm{m} \mathrm{s}^{-2}\right]$ \\
\hline$h$ & Stillwater depth $[\mathrm{m}]$ \\
\hline$H_{1}$ & First wave height $[\mathrm{m}]$ \\
\hline$l_{s}$ & Slide length (Bregoli et al. 2017) [m] \\
\hline$M$ & Relative slide mass [-] \\
\hline$m_{s}$ & Slide mass $[\mathrm{kg}]$ \\
\hline$n$ & Number of data points [-] \\
\hline$P$ & Impulse product parameter [-] \\
\hline$r$ & Radial wave propagation distance $[\mathrm{m}]$ \\
\hline$R^{*}$ & Relative surrogate radial wave propagation distance [-] \\
\hline$r^{*}$ & Surrogate radial wave propagation distance $[\mathrm{m}]$ \\
\hline
\end{tabular}




\begin{tabular}{|c|c|}
\hline$R^{2}$ & Coefficient of determination [-] \\
\hline$R_{0}$ & Relative impact radius [-] \\
\hline$r_{0}$ & Impact radius $[\mathrm{m}]$ \\
\hline$S$ & Relative slide thickness [-] \\
\hline$s$ & Slide thickness $[\mathrm{m}]$ \\
\hline$t$ & Time $[\mathrm{s}]$ \\
\hline$T_{1}$ & First wave period $[\mathrm{s}]$ \\
\hline$V_{s}$ & Slide centroid velocity $\left[\mathrm{m} \mathrm{s}^{-1}\right]$ \\
\hline$x$ & transverse coordinate $[\mathrm{m}]$ \\
\hline$x_{\max }$ & Distance from the impact location of $a_{\max }$ by Bregoli et al. (2017) [m] \\
\hline$y$ & streamwise coordinate $[\mathrm{m}]$ \\
\hline$Y_{1}$ & Relative first wave height [-] \\
\hline$z$ & vertical coordinate $[\mathrm{m}]$ \\
\hline$\alpha$ & Slide impact angle $\left[{ }^{\circ}\right]$ \\
\hline$\alpha_{\text {eff }}$ & Effective slide impact angle, $\alpha_{\text {eff }}=(6 / 7) \alpha\left[^{\circ}\right]$ \\
\hline$\gamma$ & Wave propagation angle $\left[{ }^{\circ}\right]$ \\
\hline$\Delta_{\text {meas }}$ & Deviation of measured values from predicted \\
\hline$\eta$ & Water surface displacement $[\mathrm{m}]$ \\
\hline$\theta$ & Basin side angle $\left[{ }^{\circ}\right]$ \\
\hline$\rho_{g}$ & Grain density $\left[\mathrm{kg} \mathrm{m}^{-3}\right]$ \\
\hline$\rho_{s}$ & Bulk slide density $\left[\mathrm{kg} \mathrm{m}^{-3}\right]$ \\
\hline$\rho_{w}$ & Water density $\left[\mathrm{kg} \mathrm{m}^{-3}\right]$ \\
\hline
\end{tabular}


This material may be downloaded for personal use only. Any other use requires prior permission of the American Society of Civil Engineers. This material may be found at https://doi.org/10.1061/(ASCE)WW.1943-5460.0000514.

\section{References}

Bornhold, B. D., Harper, J. R., McLaren, D., and Thomson, R. E. (2007). "Destruction of the first nations village of Kwalate by a rock avalanche-generated tsunami." Atmosphere-Ocean, 45(2), 123-128. https://doi.org/10.3137/ao.450205

Bregoli, F., Bateman, A., and Medina, V. (2017). "Tsunamis generated by fast granular landslides: 3D experiments and empirical predictors.” Journal of Hydraulic Research, 55(6), 743-758. https://doi.org/10.1080/00221686.2017.1289259

Chen, Y. Y., Kharif, C., Yang, J. H., Hsu, H. C., Touboul, J., and Chambarel, J. (2015). “An experimental study of steep solitary wave reflection at a vertical wall." European Journal of Mechanics - B/Fluids, 49, 20-28. https://doi.org/10.1016/j.euromechflu.2014.07.003

Dahl-Jensen, T., Larsen, L. M., Pedersen, S. A. S., Pedersen, J., Jepsen, H. F., Pedersen, G., Nielsen, T., Pedersen, A. K., von Platen-Hallermund, F., and Weng, W. (2004). "Landslide and Tsunami 21 November 2000 in Paatuut, West Greenland." Natural Hazards, 31(1), 277-287.

https://doi.org/10.1023/B:NHAZ.0000020264.70048.95

Dean, R. G., and Dalrymple, R. A. (1991). Water Wave Mechanics for Engineers and Scientists. World Scientific Publishing Company. https://doi.org/10.1142/9789812385512

Di Risio, M., De Girolamo, P., and Beltrani, G. M. (2011). "Forecasting Landslide Generated Tsunamis: a Review”. The Tsunami Threat - Research and Technology (N.-A. Mörner, ed.), InTech. https://doi.org/10.5772/13767

Di Risio, M., and Sammarco, P. (2008). “Analytical modeling of landslide-generated waves.” J. Waterway, Port, Coastal, Ocean Eng., 134(1), 53-60. https://doi.org/10.1061/(ASCE)0733-950X(2008)134:1(53)

Evers, F. M. (2017). "Spatial propagation of landslide generated impulse waves.” Doctoral Dissertation No 24650 and VAW-Mitteilung 244 (R. Boes, ed.), ETH Zurich, Zürich. https://doi.org/10.3929/ethz-b-000209471

Evers, F. M. (2018). "Hydraulic scale model experiments on spatial propagation of landslide generated impulse waves [Dataset].” Zenodo. https://doi.org/10.5281/zenodo.1069077

Evers, F. M., and Hager, W. H. (2015a). "Impulse wave generation: Comparison of free granular with meshpacked slides.” J. Mar. Sci. Eng., 3, 100-110. https://doi.org/10.3390/jmse3010100

Evers, F. M., and Hager, W. H. (2015b). "Videometric water surface tracking: towards investigating spatial impulse waves." Proc., 35 ${ }^{\text {th }}$ IAHR Congress, The Hague. https://doi.org/10.3929/ethz-a-010630706

Evers, F. M., and Hager, W. H. (2016a). "Spatial impulse waves: wave height decay experiments at laboratory scale.” Landslides, 13(6), 1395-1403. https://doi.org/10.1007/s10346-016-0719-1

Evers, F. M., and Hager, W. H. (2016b). "Generation and spatial propagation of landslide generated impulse waves.” Coastal Engineering Proceedings, 35(1). https://doi.org/10.9753/icce.v35.currents.13

Evers, F. M., Schmocker, L., Fuchs, H., Schwegler, B., Fankhauser, A. U., and Boes, R. M. (2018). "Landslide generated impulse waves: assessment and mitigation of hydraulic hazards.” Proc., ICOLD Congress 2018, Vienna.

Frank, P.-J., and Hager, W. H. (2014). "Spatial dike breach: Accuracy of photogrammetric measurement system.” Proc., River Flow 2014. https://doi.org/10.1201/b17133-219

Fritz, H. M., Hager, W. H., and Minor, H. E. (2004). "Near field characteristics of landslide generated impulse waves." J. Waterway, Port, Coastal, Ocean Eng., 130(6), 287-302. https://doi.org/10.1061/(ASCE)0733950X(2004)130:6(287) 
This material may be downloaded for personal use only. Any other use requires prior permission of the American Society of Civil Engineers. This material may be found at https://doi.org/10.1061/(ASCE)WW.1943-5460.0000514.

Fuchs, H., and Hager, W. H. (2015). "Solitary impulse wave transformation to overland flow." J. Waterway, Port, Coastal, Ocean Eng., 141(5), 04015004. https://doi.org/10.1061/(ASCE)WW.1943-5460.0000294

Genevois, R., and Ghirotti, M. (2005). “The 1963 Vaiont landslide.” Giornale di Geologia Applicata, 1(1), 4152. https://doi.org/10.1474/GGA.2005-01.0-05.0005

George, D. L., Iverson, R. M., and Cannon, C. M. (2017). "New methodology for computing tsunami generation by subaerial landslides: Application to the 2015 Tyndall Glacier landslide, Alaska." Geophys. Res. Lett., 44, 7276-7284. https://doi.org/10.1002/2017GL074341

Heller, V., Hager, W. H., and Minor H.-E. (2008) "Scale effects in subaerial landslide generated impulse waves." Exp. Fluids, 44(5), 691-703. https://doi.org/10.1007/s00348-007-0427-7

Heller, V., Hager W. H., and Minor, H.-E. (2009). "Landslide generated impulse waves in reservoirs: Basics and computation.” VAW-Mitteilung 211 (H.-E. Minor, ed.), ETH Zurich, Zürich.

Heller, V., and Hager, W. H. (2010). "Impulse product parameter in landslide generated impulse waves." $J$. Waterway, Port, Coastal, Ocean Eng., 136(3), 145-155. https://doi.org/10.1061/(ASCE)WW.19435460.0000037

Heller, V., and Hager, W. H. (2011). "Wave types of landslide generated impulse waves.” Ocean Engineering, 38(4): 630-640. https://doi.org/10.1016/j.oceaneng.2010.12.010

Heller, V., Moalemi, M., Kinnear, R. D., and Adams, R. A. (2012). “Geometrical effects on landslide-generated tsunamis.” Journal of Waterway, Port, Coastal, and Ocean Engineering, 138(4), 286-298. https://doi.org/10.1061/(ASCE)WW.1943-5460.0000130

Heller, V., and Spinneken, J. (2015). "On the effect of the water body geometry on landslide-tsunamis: Physical insight from laboratory tests and 2D to 3D wave parameter transformation." Coast. Eng., 104, 113-134. https://doi.org/10.1016/j.coastaleng.2015.06.006

Higman, B., Shugar, D. H., Stark, C. P., Ekström, G., Koppes, M. N., Lynett, P., Dufresne, A., Haeussler, P. J., Geertsema, M., Gulick, S., Mattox, A., Venditti, J. G., Walton, M. A. L., McCall, N., Mckittrick, E., MacInnes, B., Bilderback, E. L., Tang, H., Willis, M. J., Richmond, B., Reece, R. S., Larsen, C., Olson, B., Capra, J., Ayca, A., Bloom, C., Williams, H., Bonno, D., Weiss, R., Keen, A., Skanavis, V., and Loso, M. (2018). "The 2015 landslide and tsunami in Taan Fiord, Alaska." Sci. Rep. UK, 8, 12993. https://doi.org/10.1038/s41598-01830475-w

Huber, A., and Hager, W. H. (1997). "Forecasting impulse waves in reservoirs." Proc., 19 $9^{\text {th }}$ Congrès des Grands Barrages Florence, C.31, 993-1005. ICOLD, Paris.

Hughes, S. A. (1993). Physical models and laboratory technique. Advanced Series on Ocean Engineering 7 (P. L. F. Liu, ed.), World Scientific Publishing, Singapore. https://doi.org/10.1142/9789812795939

Kamphuis, J. W., and Bowering, R. J. (1970). "Impulse waves generated by landslides.” Proc., 12th Coastal Engineering Conf., Vol. 1, ASCE, New York, 575-588. https://doi.org/10.1061/9780872620285.035

Kobel, J., Evers, F. M., and Hager, W. H. (2017). “Impulse wave overtopping at rigid dam structures.” J. Hydraul. Eng., 143(6), 04017002. https://doi.org/10.1061/(ASCE)HY.1943-7900.0001271

McFall, B. C., and Fritz, H. M. (2016). "Physical modelling of tsunamis generated by three-dimensional deformable granular landslides on planar and conical island slopes.” Proc. R. Soc. A, 472(2188), 20160052. https://doi.org/10.1098/rspa.2016.0052

McFall, B. C., and Fritz, H. M. (2017). "Runup of granular landslide-generated tsunamis on planar coasts and conical islands.” J. Geophys. Res. Oceans, 122(8), 6901-6922. https://doi.org/10.1002/2017JC012832 
This material may be downloaded for personal use only. Any other use requires prior permission of the American Society of Civil Engineers. This material may be found at https://doi.org/10.1061/(ASCE)WW.1943-5460.0000514.

Miller, D. J. (1960). "The Alaska earthquake of July 10, 1958: giant wave in Lituya Bay." Bulletin of the Seismological Society of America, 50(2), 253-266.

Mohammed, F., and Fritz, H. M. (2012). "Physical modeling of tsunamis generated by three-dimensional deformable granular landslides.” J. Geophys. Res., 117, C11015. https://doi.org/10.1029/2011JC007850

Müller, D. R. (1995). “Auflaufen und Überschwappen von Impulswellen an Talsperren (Run-up and overtopping of impulse waves at dams).” VAW-Mitteilung 137 (D. Vischer, ed.), ETH Zurich, Zürich (in German).

Panizzo, A., De Girolamo, P., and Petaccia, A. (2005). "Forecasting impulse waves generated by subaerial landslides.” J. Geophys. Res., 110, C12025. https://doi.org/10.1029/2004JC002778

Poli, P. (2017). "Creep and slip: Seismic precursors to the Nuugaatsiaq landslide (Greenland)." Geophys. Res. Lett., 44, 8832-8836. https://doi.org/10.1002/2017GL075039

Przadka, A., Cabane, B., Pagneux, V., Maurel, A., and Petitjeans, P. (2012). "Fourier transform profilometry for water waves: how to achieve clean water attenuation with diffusive reflection at the water surface?." Exp. fluids, 52(2), 519-527. https://doi.org/10.1007/s00348-011-1240-x

Risley, J. C., Walder, J. S., and Denlinger, R. P. (2006). "Usoi dam wave overtopping and flood routing in the Bartang and Panj rivers, Tajikistan.” Nat. Hazards, 38(3), 375-390. https://doi.org/10.1007/s11069-005-1923-9

Roberts, N. J., McKillop, R., Hermanns, R. L., Clague, J. J., and Oppikofer, T. (2014). "Preliminary global catalogue of displacement waves from subaerial landslides." Landslide Science for a Safer Geoenvironment 3 (K. Sassa, P. Canuti, Y. Yin, eds.), 687-692. https://doi.org/10.1007/978-3-319-04996-0_104

Roberts, N. J., McKillop, R. J., Lawrence, M. S., Psutka, J. F., Clague, J. J., Brideau, M.-A., and Ward, B. C. (2013). "Impacts of the 2007 landslide-generated tsunami in Chehalis Lake, Canada." Landslide Science and Practice 6 (C. Margottini, P. Canuti, K. Sassa, eds.), 133-140. https://doi.org/10.1007/978-3-642-31319-6_19

Sepúlveda, S. A., Serey, A., Lara, M., Pavez, A., and Rebolledo, S. (2010). "Landslides induced by the April 2007 Aysén Fjord earthquake, Chilean Patagonia." Landslides, 7(4), 483-492. https://doi.org/10.1007/s10346010-0203-2

Synolakis, C. E. (1989). “Are solitary waves the limiting waves in long wave runup?.” Coastal Engineering Proceedings, 21, 219-233. https://doi.org/10.1061/9780872626874.015

Wang, J., Ward, S. N., and Xiao, L. (2015). "Numerical simulation of the December 4, 2007 landslide-generated tsunami in Chehalis Lake, Canada.” Geophys. J. Int., 201(1), 372-376. https://doi.org/10.1093/gji/ggv026

Zweifel, A., Hager, W. H., and Minor, H. E. (2006). "Plane impulse waves in reservoirs.” J. Waterway, Port, Coastal, Ocean Eng., 132(5), 358-368. https://doi.org/10.1061/(ASCE)0733-950X(2006)132:5(358) 